\title{
Electrolyte disorders in cancer patients: a systematic review
}

\author{
Rossana Berardi, Mariangela Torniai, Edoardo Lenci, Federica Pecci, Francesca Morgese, Silvia Rinaldi \\ Clinica Oncologica, Università Politecnica delle Marche, Azienda Ospedaliero-Universitaria Ospedali Riuniti Umberto I - GM \\ Lancisi - G Salesi, Ancona 60126, Italy.
}

Correspondence to: Prof. Rossana Berardi, Clinica Oncologica, Università Politecnica delle Marche, Azienda OspedalieroUniversitaria Ospedali Riuniti di Ancona, Via Conca 71, Ancona 60126, Italy. E-mail: r.berardi@univpm.it

How to cite this article: Berardi R, Torniai M, Lenci E, Pecci F, Morgese F, Rinaldi S. Electrolyte disorders in cancer patients: a systematic review. J Cancer Metastasis Treat 2019;5:79. http://dx.doi.org/10.20517/2394-4722.2019.008

\author{
Received: 26 Apr 2019 First Decision: 26 Jul 2019 Revised: 20 Nov 2019 Accepted: 20 Nov 2019 Published: 9 Dec 2019 \\ Science Editor: Stephen J. Ralph Copy Editor: Jing-Wen Zhang Production Editor: Jing Yu
}

\begin{abstract}
Electrolyte disorders are very common complications in cancer patients. They might be associated to a worsening outcome, influencing quality of life, possibility to receive anticancer drugs, and conditioning survival. In fact, they might provoke important morbidity, with dysfunction of multiple organs and rarely causing life-threatening conditions. Moreover, recent studies showed that they might worsen cancer patients' outcome, while a prompt correction seems to have a positive impact. Furthermore, there is evidence of a correlation between electrolyte alterations and poorer performance status, delays in therapy commencement and continuation, and negative treatment outcomes. These alterations usually involve sodium, potassium, calcium, and magnesium serum levels. Several causes might contribute to electrolyte disorders in cancer patients: cancer effects, such as paraneoplastic syndrome of inappropriate antidiuresis and tumor lysis syndrome; anti-cancer therapies; and other concomitant clinical conditions or treatments. However, the origin of the electrolyte disorder is often multifactorial, thus identifying and correcting the causes is not always feasible. Furthermore, they are often not recognized or not considered in clinical practice, worsening these alterations and patient condition. An improvement of knowledge about the physiological mechanisms underlying electrolyte disorders is necessary to strengthen their identification and set up a prompt, adequate, and effective treatment. The aim of this systematic review is to provide an analysis of the pathophysiological mechanisms of electrolyte abnormalities in cancer patients to facilitate their identification, management, and therapy to improve patient outcome.
\end{abstract}

Keywords: Cancer, electrolyte disorders, hyponatremia, syndrome of inappropriate antidiuresis, hyperkalemia, hypocalcemia, hypomagnesemia

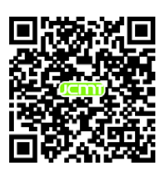




\section{INTRODUCTION}

Electrolyte disorders are very common conditions in cancer patients. They mainly concern changes in serum sodium, potassium, calcium, and magnesium levels. In most cases, these alterations are asymptomatic and therefore not always taken into consideration in clinical practice. However, they can sometimes be associated with clinical manifestations that can worsen patient's clinical condition up to more serious life-threatening events. Furthermore, several clinical studies showed an important impact of electrolyte disorders on cancer patients' journey. Firstly, they seem to correlate with a worsening quality of life and performance status, reduced probability of tumor response to anti-cancer treatment and treatment delays, and cause poorer outcomes and reduced survival ${ }^{[1]}$. Electrolyte disorders in cancer patients might depend on several causes: cancer physiopathology, anti-tumor treatments, concomitant clinical conditions, or therapies. However, they often have a multifactorial origin and they might be both secondary and responsible for multiple organ systems' dysfunction. A prompt correction of electrolyte disorders is commonly associated with a better prognosis. Therefore, increasing attention towards electrolyte disturbances is emerging in the literature and clinical trials ${ }^{[2]}$. Ingles Garces et al. ${ }^{[3]}$ published a review on phase I trials performed between 2011 and 2015. They showed elevated rates of hyponatremia (62\%), hypokalemia (40\%), hypomagnesemia (17\%), and hypocalcemia (12\%) in cancer patients treated with new anticancer-agents and that patients who developed adverse events in terms of electrolyte disturbances during follow-up had a poorer median overall survival (26 weeks $v s .37$ weeks, hazard ratio $=1.61 ; P<$ $0.001)$. These data suggest the importance of monitoring and correcting electrolyte disorders in cancer patients. The relationship between electrolyte disorders and poor prognostic impact on cancer patients might depend on the fact that several ion channels and transporters are over- or under-expressed in cancer cells and implicated in phenomena of cell proliferation, apoptosis, migration, and invasiveness ${ }^{[4]}$. Recently, it has been demonstrated that several channel genes are expressed in several cancer types, suggesting an important role in tumor development and progression. For example, a recent study proposed an ion channel gene signature for breast cancer as a prognostic and diagnostic biomarker, showing an association between different ion gene expression and p53 mutation status, estrogen receptor status, and grading ${ }^{[5]}$.

Our review aims to focus on electrolyte disorders in cancer patients, providing information for correct and prompt diagnosis, therapy, and monitoring, in order to improve the outcome of the patients.

\section{SODIUM}

Sodium is the major cation of extracellular fluid (ECF) and the main constituent of serum osmolality. Its concentration in ECF is essential for maintaining the circulating blood volume and it is strictly interdependent of water presence. Normal serum sodium level is $135-145 \mathrm{mmol} / \mathrm{L}$ and its imbalance may be caused by alteration of both solute and water intake, depletion, and dilution ${ }^{[6]}$.

Several integrated systems are involved in maintaining normal serum sodium concentration, such as regulation of water intake by thirst, control of free water renal excretion by antidiuretic hormone secretion, renal sodium excretion by glomerular filtration, peritubular conditions, and adrenal aldosterone secretion.

In particular, the angiotensin II arginine vasopressin (AVP) - atrial natriuretic peptide pathway is the most important mechanism of sodium balance ${ }^{[7]}$, and it is strictly associated to serum osmolality ${ }^{[8]}$.

Alterations in serum sodium concentration include hyponatremia and hypernatremia. Sodium channels have been described in cancer cells and associated with a more aggressive behavior ${ }^{[4]}$. Voltage-gated sodium channels (VGSC) are a large group of trans-membrane proteins that allow the flow of sodium ions down the electrochemical gradient through cell membranes. In particular, overexpression of Nav 1.5, a VGSC, seems to promote cell proliferation, migration, invasion, and metastasis of oral squamous cell 
carcinoma $^{[9]}$, breast cancer ${ }^{[10]}$, and cervical carcinoma ${ }^{[11]}$. The expression of a particular VGSC, SCN9A, in prostate cancer is associated with higher risk of metastasis due to its activity promoting cell migration. Furthermore, it is overexpressed in prostate cancer cells, compared to normal cells, representing a potential diagnostic biomarker ${ }^{[12]}$. VGSCs are overexpressed in non-small-cell lung cancer cells and involved in cell invasiveness. Recent data show that the upregulation of $\mathrm{SCN} 9 \mathrm{~A}$ in non small cell lung cancer is regulated by EGFR signaling and it is crucial for the invasive behavior of cancer cells, suggesting a potential new biomarker and therapeutic target ${ }^{[13]}$. Nav 1.5 (SCN5A) was found overexpressed also in colorectal cancer (CRC) cells compared to normal colon tissues. SCNA5 was demonstrated to regulate CRC invasion process. In fact, it is involved in activation of several pathways: Wnt signaling, steroid metabolic process, favoring cell migration, ectoderm development, and influencing cell cycle control ${ }^{[14]}$. Finally, a recent multicenter study identified two single nucleotide polymorphisms of VGSC genes (the intron SNP SCN4A-rs2302237 and the SCN10A-rs12632942 SNP) that were associated with oxaliplatin-induced peripheral neuropathy development, which is interesting as the majority of patients with CRC are given oxaliplatin ${ }^{[15]}$.

Serum sodium concentration is also regulated by aquaporins (AQP), or water channels, a large family of membrane proteins involved in water transportation between cells. AQP1 might be expressed in breast cancer cells and it is associated with aggressive behavior. In fact, it correlates with higher grading, CK14 expression, smooth muscle actin expression, basal-like group, and poor prognosis ${ }^{[16]}$. Aquaporin's expression has also been investigated in CRC. In particular, AQP1, AQP3, and AQP5 are expressed in CRC cell lines and in primary CRC. They have been described during CRC progression and in liver metastases ${ }^{[17]}$. AQP5 over-expression was demonstrated to be associated with worse TNM stage, grading, and lymph node involvement ${ }^{[18]}$. AQP3 expression is positively regulated by endothelial growth factor pathway and it is associated with lymph node involvement, metastasis, and tumor differentiation ${ }^{[19]}$. Furthermore, a recent study showed that reduced $A Q P 9$ gene expression is associated with a lack of response to adjuvant chemotherapy ${ }^{[20]}$. AQP3 and AQP5 are also over-expressed in esophageal cancer cells compared to normal tissue and their co-expression seems to have a negative prognostic role ${ }^{[21]}$. The coexpression of AQP3 and AQP5, also described in gastric cancer, is associated with lymph node involvement and intestinal type $\mathrm{e}^{[22]}$.

Although the effect of serum sodium concentrations' alterations on the functionality of VGSCs and AQP in tumor cells is still unknown, many data are emerging on the effect of dysnatremic conditions in neurons. In particular, a hyponatremic condition induces a modification of the axonal $\mathrm{Na}^{+}$channels kinetics, resulting in a decreased $\mathrm{Na}^{+}$current. Moreover, the damage is proportional to the severity of hyponatremia and concerns the recovery phase of VGSC. On the other hand, hypernatremia increases the excitability of the membrane, reducing the response time of the channel. However, the effect of hyponatremic condition seems to be less destructive compared to situation of hyponatremia on the activity of $\mathrm{Na}$ ion channel $^{[23]}$. Syndrome of inappropriate antidiuresis (SIAD) is a rare cancer paraneoplastic syndrome causing hyponatremia. It is associated with overexpression of AQP in renal cells. Even though no data are available on AQP expression in cancer cells, secondary to SIAD, dysnatremia could also play a role in AQP expression in cancer cells ${ }^{[1]}$. These data suggest that alterations in serum sodium concentration might play an important role on the functionality of tumor cells that overexpress sodium channels and AQPs.

Finally, the importance of sodium in oncology is also underlined by another potential development field, sodium magnetic resonance imaging $\left({ }^{23} \mathrm{NaMRI}\right) .{ }^{23} \mathrm{NaMRI}$ seems to be able to provide information on cells' metabolism and their physiology, exploiting the different total tissue sodium concentration between healthy tissue and neoplastic cells. ${ }^{23} \mathrm{NaMRI}$ takes advantage of the abnormally high sodium concentration of proliferating cells, due to altered $\mathrm{pH}$ and $\mathrm{Na}^{+} / \mathrm{H}^{+}$transport kinetics. Currently, the most promising application areas of ${ }^{23} \mathrm{NaMRI}$ are the early diagnosis of brain tumors and breast cancer ${ }^{[24]}$. 


\section{Hyponatremia}

Definition and clinical implications

Hyponatremia is defined as a serum/plasma sodium concentration lower than $135 \mathrm{mmol} / \mathrm{L}$. It can arise rapidly within $48 \mathrm{~h}$ (acute hypernatremia) or, more frequently, slowly (chronic hypernatremia). According to its serum level, it can be classified into three severity grades: mild (130-134 mEq/L), moderate (125-129 mEq/L), and severe $(<125 \mathrm{mEq} / \mathrm{L})^{[25]}$.

It represents the most common tumor-related electrolyte disorder. Even though its accurate incidence is still unknown because different serum sodium cut-off levels were considered in several studies, a variable incidence of $4 \%-44 \%$ was reported, depending on cancer type and clinical setting ${ }^{[26]}$. Higher incidences are associated with thoracic neoplasms, and, in particular, it occurs more frequently in patients with small-cell lung cancer, with a median estimated rate of $15 \%{ }^{[26]}$.

Several studies evaluated the impact of hyponatremia on cancer patients, showing that, independently of causes, it negatively correlates with patients' outcome ${ }^{[27]}$. In particular, hyponatremia seems associated to poorer performance status ${ }^{[28]}$ and reduced survival in patients with lung cancer ${ }^{[29]}$, renal cell carcinoma ${ }^{[30]}$, malignant pleural mesothelioma ${ }^{[31]}$, gastric cancer ${ }^{[32]}$, colon-rectal cancer ${ }^{[33]}$, and lymphoma ${ }^{[34]}$. Recent evidence shows an important negative predictive role of hyponatremia, for patients receiving both chemotherapy and target therapy ${ }^{[35]}$, while a prompt correction of this electrolyte disorder improves patients' outcome, which takes into account the correct timing to avoid neurological damage ${ }^{[36]}$. Furthermore, hyponatremia seems to also have a negative role in hospitalized patients, as it was demonstrated to be associated with a longer length of hospital stay, inducing a negative impact on quality of live and prognosis and an increase in hospitalization $\operatorname{costs}^{[37]}$.

\section{Causes}

In cancer patients, several causes might induce hyponatremia ${ }^{[1]}$ :

(1) Cancer: paraneoplastic syndromes such as SIAD, brain metastasis, adrenal metastasis, and kidney metastasis can cause hyponatremia.

(2) Cancer-treatment: it can cause hyponatremia as a direct effect of their mechanism of action (vinca alkaloids might induce SIAD; platinum derivates are frequently associated to hyponatremia; and target therapies, in particular antiangiogenetic agents, seem to induce hyponatremia, despite the underlying mechanism being unknown) or as a result of side effects such as gastrointestinal losses (vomiting and diarrhea caused by most of chemotherapeutic agents, target therapies, and immunotherapy), kidney loss, and heart failure (cardiotoxic drugs such as anthracyclines and target therapies such as anti HER-2, antiALK, and anti-MEK). Immunotherapeutic agents might cause direct damage to adrenal or pituitary gland, favoring hyponatremia development.

(3) Concomitant drugs: diuretics, antibiotics, non-steroidal anti-inflammatory drugs (NSAIDs), opioids, antidepressants, and neuroleptics can induce hyponatremia.

(4) Concomitant diseases: heart failure, kidney failure, thyroiditis, hypercortisolism, liver cirrhosis, pneumonia, and inflammatory lung or brain diseases can induce hyponatremia.

However, in most cases, more than one of the aforementioned factors might induce hyponatremia in cancer patients.

These causes can be traced back to two different basic mechanisms: excessive free water (for increased intake or reduced elimination) or, rarely, sodium loss (reduced intake or increased loss). The knowledge 
Table 1. Causes of hyponatremia

\begin{tabular}{ll}
\hline Extracellular volume & \multicolumn{1}{c}{ Causes of hyponatremia } \\
\hline Hypovolemic: increased water loss & Gastrointestinal losses (vomiting, diarrhea) \\
& Renal losses (nephropathies, M. Addison, Diuretics) \\
& Cerebral salt wasting syndrome \\
Euvolemic: salt loss & Syndrome of inappropriate antidiuresis \\
& Endocrine dysfunctions (hypercortisolism, hypothyroidism) \\
Hypervolemic: water retention & Edematogenic syndromes (cirrhosis, heart failure, kidney failure, nephrotic syndrome) \\
\hline
\end{tabular}

of these two different mechanisms is fundamental for the differential diagnosis between the potential causes in order to set a correct therapeutic approach. Extracellular volume (ECV) status is fundamental to distinguishing the mechanism underlying hyponatremia.

According to ECV status, hyponatremia can be classified in [Table 1]:

- Hypovolemic, with reduced ECV.

- Euvolemic, with normal ECV.

- Hypervolemic, with increased ECV.

Hypovolemic hyponatremia is often due to water loss, namely gastrointestinal loss (vomiting, diarrhea), renal losses, bleeding, and cerebral salt wasting, caused by a dysfunction of hypothalamic-renal axis.

Euvolemic hyponatremia, despite being rare, is an important and frequent condition in cancer patients. Several mechanisms induce euvolemic hyponatremia such as adrenal insufficiency, hypothyroidism, and SIAD. SIAD is the principal cause of hyponatremia in oncological and hospitalized patients, occurring in $1 \%-2 \%$ of all subjects and in $30 \%$ of cancer patients ${ }^{[26]}$. It is characterized by a deregulated AVP activity, which induces a lower free water excretion. The relative free water surplus leads to serum euvolemic hypoosmolar hyponatremia. It is often due to a paraneoplastic syndrome, related to several kinds of tumors. It is most frequently reported in patients with small-cell lung cancer, but it is also described in patients with non-small-cell lung cancer, head and neck cancer, and, rarely, other malignancies ${ }^{[26]}$.

SIAD may be caused by ${ }^{[38]}$ :

- Inappropriate secretion of antidiuretic hormone (ADH) from cancer cells (paraneoplastic syndrome).

- Activating mutation of ADH receptor V2.

- Inappropriate or persistent release of AVP.

Although paraneoplastic syndrome is the most frequent cause of SIAD, it should be considered that many conditions might lead to an inappropriate release of AVP in cancer patients ${ }^{[39,40]}$ :

- Concomitant drugs: diuretics, analgesics, chemotherapies, anticancer target agents, antidepressants, antipsychotics, antiepileptics, and antiemetics.

- Central nervous system disease: expansive lesions such as neoplasms or hematomas, inflammatory diseases (e.g., encephalitis, meningitis, etc.), degenerative diseases (e.g., Guillain-Barré syndrome), and other rare conditions (e.g., hemorrhage, delirium tremens, hypophyseal peduncle section, transphenoidal adenectomy ${ }^{[41]}$, and hydrocephalus).

- Pulmonary disorders: infections, respiratory failure, chronic obstructive pulmonary disease, and active pressure ventilation $^{[1]}$.

- Others: AIDS, senile atrophy, and idiopathic.

Hypervolemic hyponatremia is characterized by an excess of both total body sodium and water. It occurs in edematous conditions such as cirrhosis, chronic kidney disease, nephrotic syndrome, and congestive heart failure $^{[42]}$. 
According to serum osmolality status, hyponatremia can be divided into ${ }^{[43,44]}$ :

- Hypotonic is characterized by reduced serum osmolality, due to an excess of free water compared to the sodium. This condition might be induced by an excessive water intake (e.g., primary polydipsia) or by a compromised renal water excretory capacity (SIAD).

- Hypertonic is characterized by increased serum osmolality (e.g., in glycemic decompensation).

- Isotonic is characterized by normal serum osmolality, often secondary to an artificially hyponatremia (pseudohyponatremia) due to elevated serum solutes concentrations (e.g., hyperlipidemia).

\section{Management}

A correct and timely diagnosis of hyponatremia is essential to setting up a rapid therapy and improving the prognosis of cancer patients. Diagnosis can occur from clinical suspicion, but it is essential for clinicians monitoring serum/plasma sodium level in all cancer patients, in order to promptly correct this electrolyte disturbance, when present, even in the case of symptoms' absence. Hyponatremia symptoms are often absent or generic and closely related to hyponatremia grade and onset speed ${ }^{[1]}$.

Patients with mild and/or chronic hyponatremia are often asymptomatic or present blurred symptoms that can be misunderstood or imputed to other causes (e.g., dizziness, postural instability, and asthenia).

Patients with severe and/or acute hyponatremia can present different symptoms (from gastrointestinal symptoms such as lack of appetite, nausea, and vomiting to neurological disorders such as headache, irritability, attention deficit, confusion, gait disturbances, and muscle cramps), including life-threatening conditions (bulbar paralysis, lethargy, convulsions, encephalic brain herniation, coma, and cardiorespiratory arrest).

Diagnosis of hyponatremia requires routine laboratory tests. For a correct therapeutic approach, it is crucial to identify the underlying causes, thus lab assessment should also include plasma and urine osmolality, ECV status evaluation, and urinary sodium concentration to obtain a correct differential diagnosis [Figure 1].

In particular, due to different therapeutic options, it is fundamental to exclude SIAD. SIAD diagnosis is diagnosis of exclusion, for which the main criteria are:

- Presence of hyponatremia $(<135 \mathrm{mEq} / \mathrm{L})$.

- Normal ECV.

- Lower serum osmolality $(<275 \mathrm{mOsm} / \mathrm{kg})$.

- Altered urine osmolality $(>100 \mathrm{mOsm} / \mathrm{kg})$.

- Elevated urine sodium concentration (> $30 \mathrm{mmol} / \mathrm{L})$.

- Normal renal function.

- Normal adrenal and thyroid function.

- No use of diuretics.

The therapeutic approach depends on etiology, presence of symptoms, and grade of hyponatremia [Figure 1]. Regardless of hyponatremia's cause, it is important to remember that an effective and prompt correction of serum sodium concentration improves the outcome of cancer patients ${ }^{[45]}$.

Treatment options include fluid restriction, diuretics, saline solution administration, and vaptans (selective vasopressin receptor antagonists).

Fluid restriction is a difficult therapeutic choice since it is associated with poor compliance because cancer patients often need abundant hydration for oncological therapies. Furthermore, several days are required to correct serum sodium concentrations. In the case of ECV, isotonic saline infusion should be preferred. 


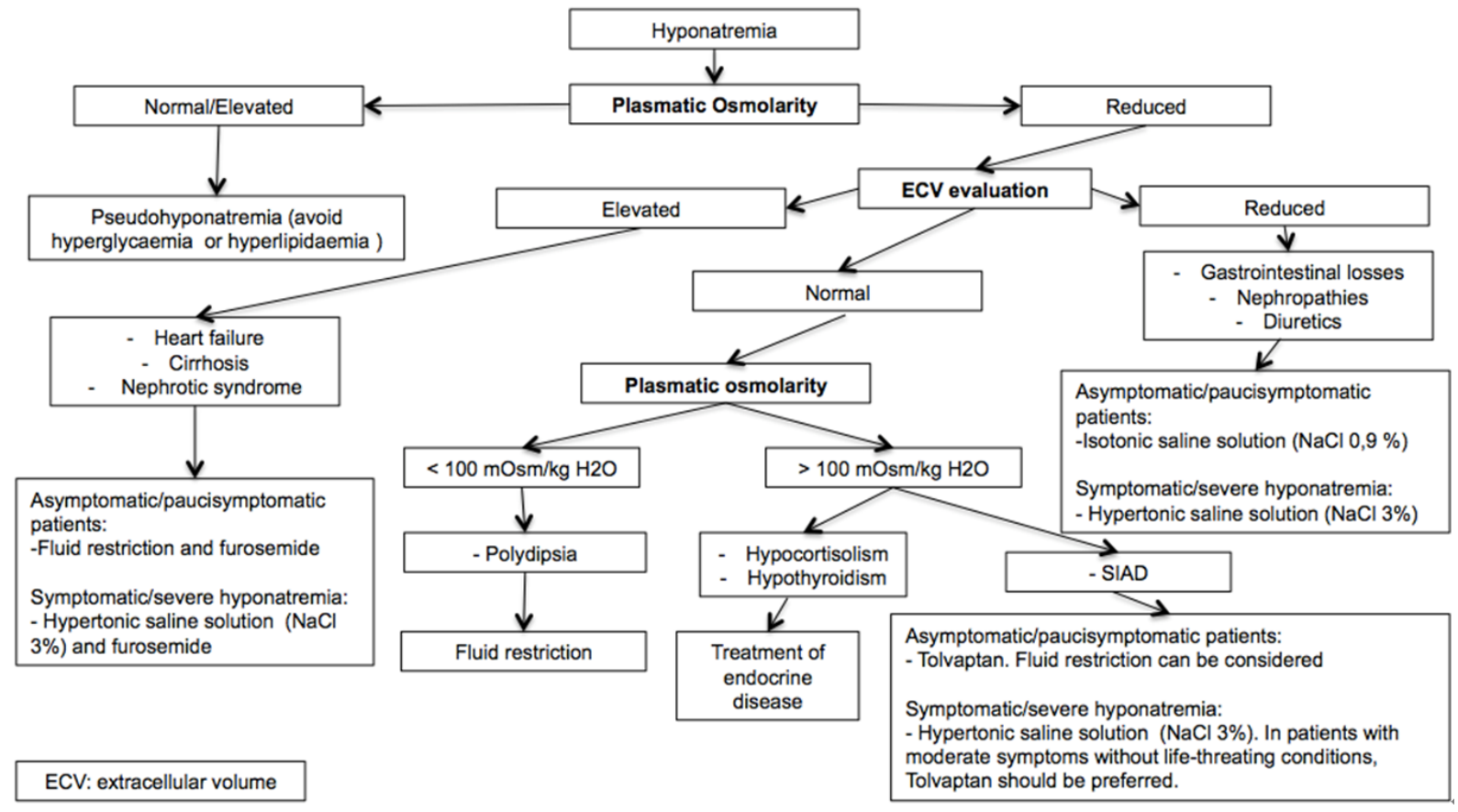

Figure 1. Hyponatremia management algorithm ${ }^{[38,44-48]}$. The correct management of hyponatremia and its treatment require the detection of its cause. Plasmatic osmolarity and ECV evaluation are necessary to recognize the origin of hyponatremia. Symptomatic hyponatremia should be treated with hypertonic saline solution. Tolvaptan should be considered in hyponatremia due to SIAD. ECV: extracellular volume; SIAD: syndrome of inappropriate antidiuresis

In the case of hyponatremia secondary to SIAD, the use of Tolvaptan, a selective V2 receptor antagonist, should be considered ${ }^{[46]}$. In fact, has shown an important efficacy to correct and stabilize serum sodium concentration, favoring the beginning and prosecution of anticancer treatments without delay. Furthermore, it seems to reduce the risk of hyponatremia development as chemotherapy adverse event ${ }^{[47]}$. Tolvaptan schedule requires starting dose of $15 \mathrm{mg}$ once daily and it should be administrated first in a hospital department to monitor the therapeutic response and any adverse event. It could be increased at 24-h intervals, when serum/plasma sodium levels are not improved, to a maximum of $60 \mathrm{mg}$ once a day ${ }^{[46]}$.

Other approved therapeutic agents are urea and Demeclocycline. However, due to their toxicity and poor patient compliance, they are no longer employed in clinical practice.

In the case of presence of severe neurological symptoms or life-threatening conditions, serum sodium levels should be corrected rapidly and the appropriate therapy is the administration of $3 \%$ hypertonic saline ${ }^{[48]}$.

It is important to monitor the rate of correction of hyponatremia since an excessive speed of rising sodium levels might cause the development of central pontine myelinolysis, an irreversible condition that leads to death. The correction rate should not exceed $12 \mathrm{mmol} / \mathrm{L} / 24 \mathrm{~h}$. Therefore, it is recommended to monitor plasma sodium levels in the first $24 \mathrm{~h}$ at regular intervals of $4-6 \mathrm{~h}$, in order to control the correction speed $^{[49]}$.

\section{Hypernatremia}

Definition and clinical implication

Hypernatremia is defined as an elevated serum sodium level over $145 \mathrm{mmol} / \mathrm{L}$. It is a frequent electrolyte disturbance occurring in $1 \%-5 \%$ of hospitalized patients. It represents a negative prognostic factor, related to an elevated mortality rate $(40 \%-75 \%)$ compared to eunatremic patients ${ }^{[50]}$. 
Table 2. Causes of hypernatremia

\begin{tabular}{ll}
\hline Causes of hypernatremia & \\
\hline Euvolemic: loss of free water & Losses through skin and breath \\
& Reduced thirst stimulation \\
& Neurogenic or nephrogenic diabetes insipidus \\
Hypovolemic: loss of free water & Renal disorders (diuretics, tubular necrosis) \\
& Gastro-intestinal disorders (e.g., vomiting, nasogastric drainage, entero-cutaneous fistulae, diarrhea) \\
& Cutaneous diseases (burns, excessive sweating) \\
& Hypertonic sodium bicarbonate or hypertonic saline infusion \\
Hypervolemic: sodium & Excessive ingestion of $\mathrm{NaCl}$ \\
& Use of emetics rich in $\mathrm{NaCl}$ \\
& Enteral nutrition \\
& Urogenital injection of hypertonic saline \\
& Hypertonic dialysis \\
& Primitive hyperaldosteronism \\
& Cushing Syndrome \\
\hline
\end{tabular}

\section{Causes}

In cancer patients, several causes might induce hypernatremia [Table 2] ${ }^{[1,52]}$ :

(1) Cancer: anorexia and cancer cachexia, kidney damage, brain metastasis inducing diabetes insipidus, and gastrointestinal disorders due to cancer infiltration (e.g., fistulae and nasogastric drainage due to bowel obstruction) can induce hypernatremia.

(2) Cancer treatment: adverse events such as vomiting and diarrhea common to most anti-cancer agents (chemotherapy, TKIs, and immunotherapies) associated with reduced thirst stimulation might cause hypernatremia. Elevated serum sodium concentration might be induced also by bowel direct damage due to antiangiogenetic agents or immunotherapy. Furthermore, some chemotherapeutic agents such as ifosfamide might induce an iatrogenic diabetes insipidus.

(3) Concomitant drugs: osmotic diuretics, corticosteroids, enteral or parenteral nutrition, and hypertonic saline infusion can induce hypernatremia.

(4) Concomitant diseases: cushing syndrome might induce hypernatremia.

Two different basic mechanisms might be involved in hypernatremia development: water loss (for reduced introduction (euvolemic hypernatremia) or increased elimination (hypovolemic hypernatremia), or, rarely, accumulation of sodium (often on iatrogenic basis, hypervolemic hypernatremia). Understanding these mechanisms is crucial for a correct differential diagnosis among potential causes of hypernatremia.

The most frequent mechanism underlying hypernatremia is total body water loss due to impaired thirst stimulation. It is often associated with altered mental status conditions, such as older age, brain tumors, damage, or surgery, causing a deficit in thirst and osmoregulation ${ }^{[51]}$. Water loss can also be due to renal or extra renal disorders ${ }^{[52]}$.

Renal water loss usually is caused by osmotic diuresis (e.g., hyperglycemia, increased serum urea concentration, or administration of mannitol or hypertonic solutions) and by a treatment with diuretics ${ }^{[53]}$.

Rarely, renal water loss can be induced by insipidus diabetes, a deficit of the vasopressin-ADH-receptor system, which can have a central or a nephrogenic origin. Central insipidus diabetes is characterized by a reduced secretion of AVP, often related to a central nervous system damage (e.g., pituitary or hypothalamus neoplasms, brain surgery, or irradiation $)^{[54]}$. Nephrogenic insipidus diabetes instead depends on renal resistance to the action of AVP. It is a rarely congenic condition, more frequently related to iatrogenic effect of amphotericin B, lithium, ifosfamide, foscarnet, and streptozocin on tubular reabsorption of water ${ }^{[53]}$. 


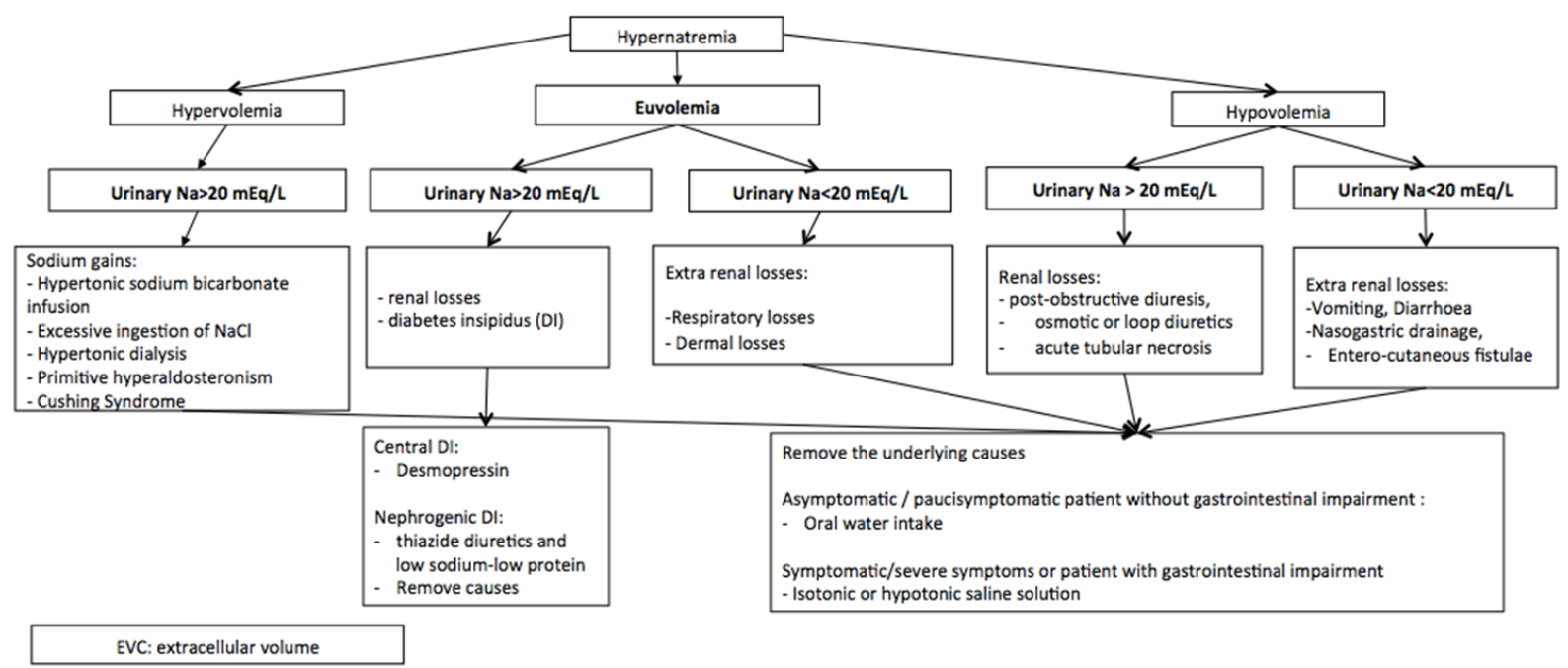

Figure 2. Algorithm of hypernatremia's management ${ }^{[48,51-60]}$. The treatment of hypernatremia in cancer patients is based on the correction of the cause. For the differential diagnosis, the evaluation of volume and urinary sodium are fundamental. DI: diabetes insipidus; EVC: extracellular volume

Extra-renal water loss is often related to gastrointestinal diseases (vomiting, nasogastric drainage, and diarrhea).

Rarely, hypernatremia can be caused by excessive salt intake. This condition is often iatrogenic and induced by parenteral administering of hypertonic solutions or chronic nutrition support with hyperosmolar or high protein feeds ${ }^{[55]}$.

\section{Management}

Hypernatremia causes neurological symptoms, for which severity is correlated with both grade and onset speed. In most cases, patients refer non-specific symptoms such as thirst, anorexia, restlessness, nausea, muscle weakness, and confusion. In the case of rapid onset or severe hypernatremia, patients might present lethargy, hyperreflexia, until convulsions, and coma ${ }^{[56]}$.

Clinical suspicion of hypernatremia should be confirmed by laboratory exam. The correct diagnosis and the detection of specific causes or predisposing factors are crucial for a correct management [Figure 2].

For a correct differential diagnosis between hyponatremia caused by excess of sodium intake and hyponatremia caused by loss of free water, the assessment of urine osmolality, urine sodium concentration, and urine volume should be obtained ${ }^{[57]}$. Concentrated urine is usually related to insufficient water intake or extra-renal losses.

Conversely, hypernatremia is associated to elevated serum osmolality and low urine osmolality renal damage with deficient capacity of urinary concentration ${ }^{[56]}$.

Hypernatremia associated to polyuria (e.g., $24 \mathrm{~h}$ urine volume exceeding $2.5 \mathrm{~L}$ ), low urine osmolality, and urinary sodium are criteria for central insipidus diabetes diagnosis ${ }^{[58]}$.

Once hypernatremia diagnosis is confirmed, the optimal management requires the removal of the cause and the correction of the electrolyte disorder based on the total ECV, restoring intravascular volume and free water. 
In collaborating and asymptomatic patients without gastrointestinal dysfunction, oral hydration is effective, and should be preferred. In patients with severe hypernatremia or unable to intake fluid orally (due to vomiting or neurological changes), intravenous hydration should be considered.

The infusion of free water ( $5 \%$ dextrose solution) should be considered in the case of loss of free water alone. Loop diuretics should be considered in the case of pure sodium gain natriuresis.

In patients with acute hypernatremia (within $24 \mathrm{~h}$ ) or severe symptoms, treatment with isotonic or hypotonic solutions should be started immediately, since it was demonstrated that a prompt correction (up to $8-12 \mathrm{mmol} / \mathrm{L}$ per day) improves patients' prognosis without risk of convulsions or cerebral edema. A correction of $1 \mathrm{mEq} / \mathrm{L} / \mathrm{h}$ should be considered safe ${ }^{[59]}$.

In patients with chronic hypernatremia or when time of onset is unknown, the correction should be obtained within $48 \mathrm{~h}$, with a reduction of serum osmolality of no more than $0.5 \mathrm{mOsm} / \mathrm{L} / \mathrm{h}$ to avoid cerebral edema onset. A reduction of serum sodium concentration of 8-10 $\mathrm{mmol} / \mathrm{L}$ per day should be considered safe. Monitoring serum sodium levels at regular intervals of $4 \mathrm{~h}$ is highly recommended to control the correction speed ${ }^{[59]}$.

Patients experiencing central insipidus diabetes should receive nasal or oral desmopressin. Nephrogenic insipidus diabetes should be treated with a combination of thiazide diuretics and low sodium-low protein, removing potential precipitation factors ${ }^{[60]}$.

\section{CALCIUM}

Calcium is an extracellular cation and the normal serum calcium concentration range is $2.1-2.5 \mathrm{mmol} / \mathrm{L}$ (8.5-10.5 mg/dL) or ionized calcium of 1.1-1.4 mmol/L (4.5-5.6 mg/dL) ${ }^{[61]}$. Most of the calcium content is deposited in the organic matrix by hydroxyapatite crystals of bones. Calcium appears in three different forms: free ion (50\%), bound to plasma proteins, and in diffusible complexes. Acid-base status influences the binding between calcium and serum proteins. In particular, alkalosis favors the binding while acidosis induces the ionized calcium form. Calcium derives from diet and it is excreted by kidney.

Calcium reabsorption in kidney occurs mainly in the proximal tubules, and a small share in the ascending loop of Henle, thus loop diuretics decrease tubular calcium resorption, whereas thiazide diuretics improve its resorption ${ }^{[62]}$. Calcium metabolism requires a steady interaction between bone and ECF. Several hormones are involved in calcium homeostasis. Parathyroid hormone (PTH), whose secretion is mediated by reduced serum calcium levels, acts on bone, favoring osteoclastic-mediated bone resorption and promoting calcium leakage and it induces the synthesis of active vitamin D and calcium intestinal absorption. Calcitonin instead, whose secretion is mediated by increased serum calcium levels, reduces the transfer of calcium from bone calcium pool to the ECF, and it decreases bone resorption inhibiting osteoclasts' activity and increases calcium renal excretion ${ }^{[63]}$.

Vitamin D also plays a crucial role in serum calcium homeostasis, favoring increased intestinal calcium absorption and bone calcium storage ${ }^{[64]}$.

Several studies demonstrated a crucial role of calcium-mediated signaling pathways in carcinogenesis, dedifferentiated into cancer stem cells, cellular motility favoring tumor invasion and metastasis, and the regulation of apoptosis ${ }^{[65]}$.

Several calcium channels are involved and expressed in cancer cells. $\mathrm{Ca}^{2+}$ ATPase I isoforms (SPCA1 and $\mathrm{ATP}_{2} \mathrm{C}_{1}$ ) are described in basal-like breast cancer, favoring cell proliferation, while calcium efflux pump 
Table 3. Causes of hypocalcemia

\begin{tabular}{ll}
\hline Causes of hypocalcemia & \\
\hline $\begin{array}{l}\text { Reduction of serum } \\
\text { calcium }\end{array}$ & $\begin{array}{l}\text { Not ionized calcium: hypoalbuminemia, nephrotic syndrome, liver disease, malnutrition } \\
\text { lonized calcium: hyperlipidemia, parenteral nutrition enriched of free fatty acid } \\
\text { Extravascular deposition: osteoblastic metastases, pancreatitis }\end{array}$ \\
& $\begin{array}{l}\text { latrogenic, post-renal obstruction, compression and infiltration by malignancy, tumor lysis syndrome, } \\
\text { hyperuricemia, sepsis, contrast agent nephropathy }\end{array}$ \\
Endocrine disorders & $\begin{array}{l}\text { Vitamin D deficiency or resistance: inadequate dietary intake, reduced absorption due to hepatobiliary or } \\
\text { intestinal malabsorption, liver disease }\end{array}$ \\
& PTH deficiency or resistance: parathyroidectomy, autoimmune disorders, hungry bone syndrome \\
Concomitant electrolyte & Hypomagnesemia \\
disorders & Hyperphosphatemia \\
Drugs & Antiepileptics: phenytoin, phenobarbital \\
& $\begin{array}{l}\text { Anticancer agents: fluorouracil, leucovorin, nab-paclitaxel, estramustine, octreotide, imatinib, axitinib, } \\
\text { panitumumab, cetuximab, cisplatin }\end{array}$ \\
& Others: bisphosphonates, denosumab, rifampicin, calcium chelators, radiographic contrast agent, \\
& furosemide, foscarnet, EDTA, cinacalcet \\
\hline
\end{tabular}

PTH: parathyroid hormone

PMCA2 (ATP2B2) is most frequently overexpressed in HER2-receptor-positive breast cancer ${ }^{[66]}$. Calcium channels are also described in androgen-responsive prostate cancer. In fact, they mediate androgeninduced effects ${ }^{[67]}$. Transient receptor potential cation channel (TRPC), subfamily C, is a group of channels expressed in cancer cells. In breast cancer, TRPC 1 correlates with low proliferation and TRPM8 overexpression correlates with ER-positive and well-differentiated lower-grade breast cancer ${ }^{[68]}$. In prostate cancer, TRPM8 expression is regulated by androgens. Decreased expressions of TRPM8 and TRCP1 are associated with the progression to androgen-independent phase and poor prognosis ${ }^{[67]}$. Contrariwise, TRPV6 ion channel's expression seems to be controlled by androgen receptors and it is highly expressed in cancer prostate cells, regardless of androgen dependence, representing a potential biomarker of cancer. In fact, it is not expressed in the healthy prostate cells and benign prostatic hyperplasia. Furthermore, its expression correlates with Gleason score and presence of metastases ${ }^{[69]}$.

\section{Hypocalcemia}

\section{Definition}

Hypocalcemia is defined as a lower serum calcium concentration (total serum calcium of $<2.1 \mathrm{mmol} / \mathrm{L}$ or $<8.5 \mathrm{mg} / \mathrm{dL}$ or ionized form of $<1.1 \mathrm{mmol} / \mathrm{L}$ or $>4.5 \mathrm{mg} / \mathrm{dL})^{[70]}$.

\section{Causes}

Several causes can induce hypocalcemia in cancer patients [Table 3]:

(1) Cancer: malnutrition due to anorexia, cancer cachexia or bowel obstruction, malabsorption related to bowel tumor infiltration or previous intestinal surgery, abnormal liver function due to liver metastasis might promote the development of hypoalbuminemia and subsequent hypocalcemia ${ }^{[70]}$. Furthermore, malabsorption and malnutrition might frequently cause vitamin D deficiency and then hypocalcemia in cancer patients ${ }^{[70]}$. Another condition leading to hypocalcemia is PTH deficiency. It is a common condition of patients undergoing total thyroidectomy with subtotal or total parathyroidectomy for cancer $^{[71]}$. Paraneoplastic disorders are also involved in hypocalcemia in cancer syndrome. Such as tumor lysis syndrome or the hungry bone syndrome. The "hungry bone syndrome" is frequent in metastatic parathyroid and prostate cancer and it is characterized by osteoblastic metastases causing an increased deposition of calcium and phosphate in bone and decreased serum calcium and phosphate concentrations $^{[72]}$.

(2) Cancer treatment: hypocalcemia is also reported in cancer patients receiving bisphosphonates or denosumab, an anti-RANKL (receptor activator of nuclear factor kappa B ligand) monoclonal antibody, employed in cancer patients with bone metastasis in order to delay or prevent skeletal-related events. In 
fact, they promote calcium deposition in the bones, reducing blood calcium concentration ${ }^{[73]}$. Therefore, checking calcium serum level before these treatments and implementation of calcium and vitamin D oral intake are recommended ${ }^{[74]}$. Furthermore, several drugs, such as chemotherapeutic agents, target therapies, immunotherapies can induce hypocalcemia in cancer patients, through different mechanisms: kidney injuries, iatrogenic magnesium-deficiency, gastrointestinal damage, pancreatitis ${ }^{[75]}$. In particular, monoclonal anti EGFR antibodies can cause hypomagnesemia with consequent hypocalcemia ${ }^{[75]}$.

(3) Concomitant drugs: diuretics and parenteral nutrition can induce hypocalcemia ${ }^{[70]}$.

(4) Concomitant diseases: kidney failure, autoimmune disorders causing PTH deficiency, sepsis, and pancreatitis can induce hypocalcemia ${ }^{[70]}$.

\section{Management}

Clinical manifestations of hypocalcemia are closely related to severity and time of onset. Symptoms and signs are influenced by other factors such as acid-base status, hypomagnesemia, and over-activity of sympathetic system $^{[76]}$.

Clinical disorders due to hypocalcemia depend on altered electrical potential of cell membrane, and it appears as an imbalanced neuromuscular excitability. Chronic and mild hypocalcemia are often asymptomatic or they can present with muscle cramps, ectopic calcifications, parkinsonism, dementia, depression, psychosis, dry skin, and cataract.

Severe or acute hypocalcemia might cause tetanic spasms, laryngospasm until generalized convulsions, and coma $^{[76]}$.

Severe hypocalcemia might also provoke cardiac alteration such as arrhythmias or heart block. ECG shows typical alteration such as prolongation of the QTc and ST interval, altered repolarization, T-wave pointed shape, or inversion ${ }^{[7]]}$.

Diagnosis of hypocalcemia is based on symptoms' presence and it needs to be confirmed through laboratory exam. Since serum calcium is partially bound to proteins, it is suggested to correct total serum calcium concentrations with albumin levels [e.g., serum calcium $(\mathrm{mg} / \mathrm{dL})+0.8 \times(4$-patient's albumin)] Alternatively, ionized calcium can be evaluated. For a correct differential diagnosis, serum albumin, total protein, urinary calcium, phosphate, vitamin $\mathrm{D}$, plasma $\mathrm{PTH}$, and parathyroid, renal, and liver function should be evaluated [Figure 3] ${ }^{[78]}$.

Treatment of hypocalcemia depends on severity, clinical manifestation, and underlying causes. When possible, it is always advisable to correct the cause of hypocalcemia ${ }^{[78]}$.

In the case of acute and/or symptomatic hypocalcemia, patients should receive intravenous calcium. To avoid adverse events, calcium gluconate should be infused slowly (e.g., $10 \mathrm{~mL}$ of a formulations of $10 \%$ calcium gluconate should be diluted in 50-100 $\mathrm{mL}$ of 5\% dextrose and infused over 5-10 min), and administered via a central venous catheter to prevent extravasation's complications ${ }^{[79]}$. In fact, a rapid correction of hypocalcemia might increase the risk of cardiac arrhythmias, especially in patients receiving digoxin, thus cardiac activity should be monitored with ECG and correction rate of hypocalcemia should be checked every 1-2 h during intravenous calcium gluconate infusion ${ }^{[79]}$.

In the case of tetanic signs due to severe and/or acute hypocalcemia, the treatment initially requires a 10-min bolus of calcium gluconate intravenous infusion $(10 \mathrm{~mL}$ of $10 \%$ solution) followed by the aforementioned formulation. Moreover, concomitant hypomagnesemia or alkalosis should be corrected ${ }^{[80]}$. 


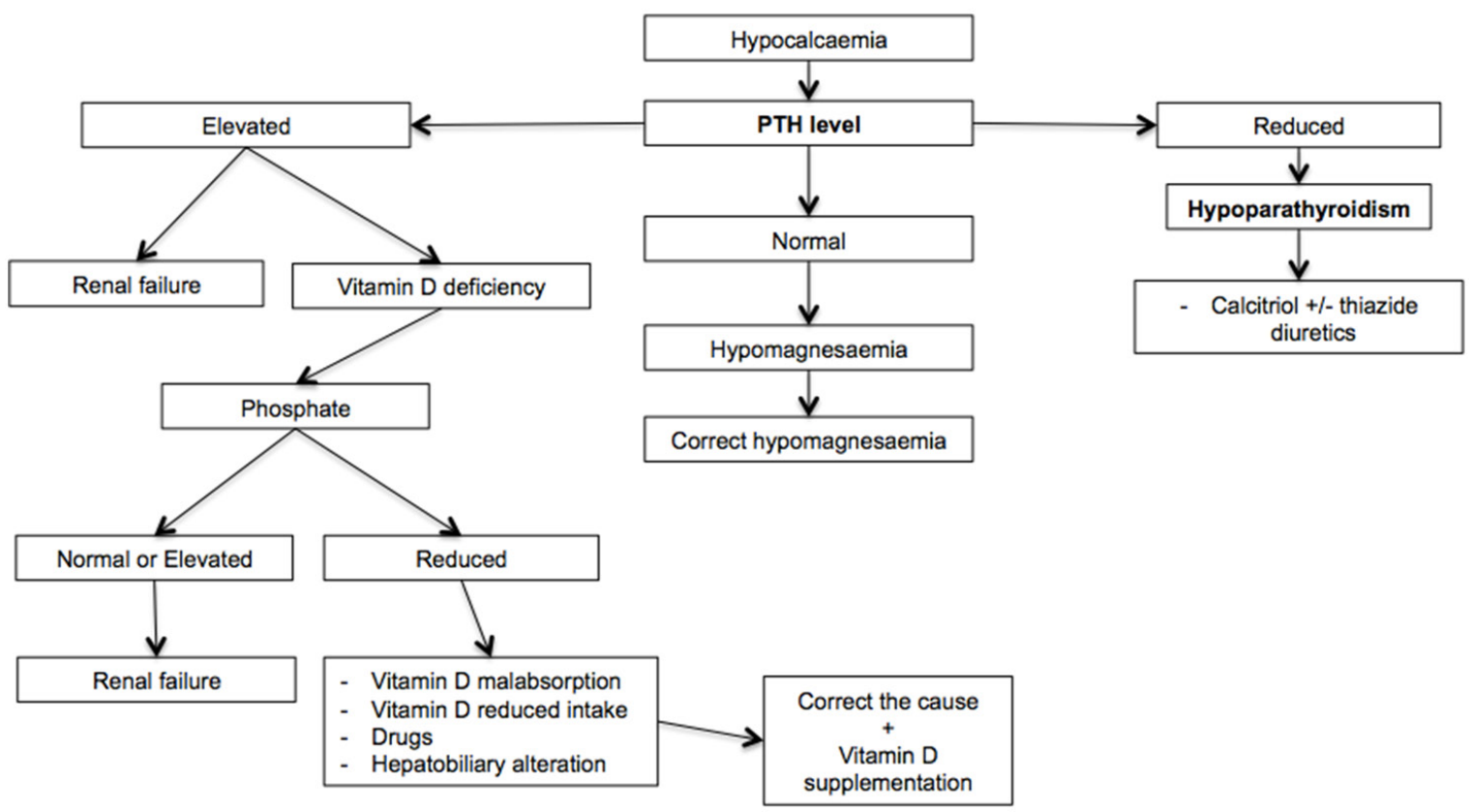

Figure 3. Algorithm of hypocalcemia management ${ }^{[48,78-86]}$. For a correct diagnostic classification of hypocalcemia, it is essential to distinguish between hypoparathyroidism and other causes through the dosage of blood parathyroid hormone. In the case of high parathormone concentrations, dosage of vitamin D is useful to exclude deficiency. PTH: parathyroid hormone

In the case of hypoparathyroidism, the treatment aims to control symptoms, maintaining adequate serum calcium levels $(2.00-2.12 \mathrm{mmol} / \mathrm{L})$, and a calcium-phosphate ratio below $4.4 \mathrm{mmol} / \mathrm{L}$, in order to prevent hypercalciuria and precipitation of calcium salts in soft tissues ${ }^{[81]}$. Calcitriol, a vitamin $\mathrm{D}$ analog, is usually used with a starting dose of $0.5 \mathrm{mcg} / \mathrm{day}$, which might be increased until adequate serum calcium concentrations are reached. Thiazide diuretics associated with a low phosphate diet could be considered ${ }^{[82]}$.

It is recommended to monitor weekly serum calcium, phosphorus concentration, and creatinine during initial administration to obtain a correct stabilization of the dose ${ }^{[83]}$.

In the case of chronic hypocalcemia, oral supplementation of calcium (calcium carbonate or calcium citrate) and vitamin D is recommended. In the case of hypomagnesemia, it should be corrected ${ }^{[84]}$.

Vitamin D insufficiency requires supplementation with oral or intramuscular ergocalciferol (vitamin D2) or oral cholecalciferol (vitamin D3). When hypocalcemia is secondary to vitamin D malabsorption, it is important to correct the underlying cause (e.g., celiac patients should receive a gluten-free diet) ${ }^{[85]}$.

Patients receiving bisphosphonates or anti-RANKL should receive oral calcium and vitamin D supplementation to prevent hypocalcemia ${ }^{[86]}$.

\section{Hypercalcemia}

\section{Definition and clinical implication}

Hypercalcemia is defined as a higher serum calcium concentration (total serum calcium over than $10.5 \mathrm{mg} / \mathrm{dL})^{[87]}$. It is a common electrolyte disorder in patients with advanced malignancies and it correlates with poor $\operatorname{prognosis}^{[88]}$.

\section{Causes}

Several causes might contribute to the development of hypercalcemia in cancer patients [Table 4]:

(1) Cancer: the main cause of hypercalcemia in cancer patients is hyperparathyroidism. It can be divided 
Table 4. Causes of hypercalcemia

\begin{tabular}{ll}
\hline Causes of hypercalcemia & \\
\hline Primary hyperparathyroidism & $\begin{array}{l}\text { Parathyroid adenoma (MEN1 and 2a), parathyroid carcinoma, familial hypocalciuric hypercalcemia, } \\
\text { isolated familial hyperparathyroidism }\end{array}$ \\
Secondary hyperparathyroidism & $\begin{array}{l}\text { Renal failure, lithium, tumors, bone metastasis } \\
\text { Lithium, thiazide diuretics, calcium containing antacids, vitamin A, estrogens, growth hormone, } \\
\text { vrugs }\end{array}$ \\
vitamin D intoxication, theophylline \\
Immobilization & $\begin{array}{l}\text { Spinal cord injury, neurological diseases, pathological fracture, orthopedic surgery } \\
\text { Chronic granulomatous disorders, hyperthyroidism, acromegaly, pheochromocytoma, adrenal } \\
\text { insufficiency, parenteral nutrition }\end{array}$ \\
\hline
\end{tabular}

into primary and secondary hyperparathyroidism. Primary hyperparathyroidism, the most common cause of hypercalcemia in the general population, is characterized by inappropriate secretion of PTH provoking elevated serum calcium concentrations. Single parathyroid carcinoma is a frequent cause of primary hyperparathyroidism, sometimes inducing a rare but life-threatening condition, hyperparathyroidisminduced hypercalcemic crisis characterized by elevated PTH concentrations (3-10 times higher than normal values) and serum calcium-levels ${ }^{[89]}$. Secondary hyperparathyroidism, instead, is characterized by elevated quantities of PTH, secreted by parathyroids. Several causes might contribute to this mechanism ${ }^{[90]}$, in particular malnutrition and cancer anorexia are the most common cancer related causes. Malignancies are an important cause of hypercalcemia. It was described as occurring in $20 \%-30 \%$ of cancer patients, especially those hospitalized, and it represents one of the most common life-threatening metabolic disorders ${ }^{[91]}$. Even though several mechanisms underlay hypercalcemia in cancer patients, it seems to be correlated, especially in some kinds of tumors (head and neck, lung, renal cell, ovarian, thyroid, endometrial, colorectal, breast cancer, hepatocarcinoma, cholangiocarcinoma, thymomas, neuroendocrine tumors, gastrointestinal stromal tumor, and leukemias), with the ectopic production of PTH or parathormone-related peptide (PTHrP). These factors seem responsible for osteoclastic activation, through an increased synthesis of RANKL, provoking bone destruction and calcium release. Furthermore, they determine an increased renal calcium reabsorption, favoring the development of metastatic calcification involving multiple organs, especially lungs, potentially resulting in pulmonary edema ${ }^{\left[g_{2}\right]}$. Moreover, bone metastases, in particular osteolytic ones, are often associated to hypercalcemia due to calcium release from bone. It represents a common cause of hypercalcemia, occurring in approximately $20 \%$ of patients with malignancy-related hypercalcemia. Bone metastasis releases several local factors, e.g., transforming growth factor $\beta$, RANKL, lymphotoxin, interleukin-1, interleukin- 6 , hepatocyte growth factor, and macrophage inflammatory protein (MIP-1alfa), that favor the release of PTHrP and bone remodeling resulting in hypercalcemia ${ }^{[93]}$. Rarely, hypercalcemia might be due to ectopic activity of 1-alpha-hydroxylase resulting in calcitriol production that promotes increased bone resorption with calcium release and intestinal calcium absorption. This mechanism is described in some kinds of tumors such as lymphomas (lymphomaassociated calcitriol production) and ovarian germ cell tumors ${ }^{[88]}$. Finally, immobilization due to bedridden patients, a common condition of advanced cancer, can favor an acceleration of bone resorption resulting in hypercalcemia ${ }^{[94]}$.

(2) Cancer treatment: antineoplastic drugs can indirectly cause hypercalcemia, for example through kidney damage ${ }^{[88]}$.

(3) Concomitant drugs: several drugs might cause hypercalcemia. Thiazide diuretics, vitamin D intoxication, and parenteral nutrition are the most common agents involved in this electrolyte disorder in cancer patients.

(4) Concomitant diseases: several pathological conditions might cause hypercalcemia. It may depend on excess of PTH (primary hyperparathyroidism due to parathyroid adenoma, familial hypocalciuric hypercalcemia, isolated familial hyperparathyroidism, or most commonly secondary hyperparathyroidism 
due to renal failure or drugs such as lithium) or arise due to mechanisms independent of PTH (chronic granulomatous disorders, hyperthyroidism, acromegaly, pheochromocytoma, and adrenal insufficiency $)^{[8-90]}$.

\section{Management}

To improve patients' outcome, a periodic monitoring of calcium serum levels and prompt correction of potential hypercalcemia should be performed. To define an effective hypercalcemia, it is important to avoid the presence of concomitant factors that can influence the share of bound and free calcium (e.g., hyperglobulinemia might increase total calcium levels without modifying ionized concentrations; acidemia and reducing albumin-calcium affinity might increase the level of the ionized form, without altering total calcium levels ${ }^{[87]}$. Diagnosis is often incidentally during routine laboratory investigations, as most patients with mild hypercalcemia are asymptomatic ${ }^{[88]}$. Chronic hypercalcemia, due to hyperparathyroidism, is often asymptomatic; however, in some cases, this long-lasting electrolyte disorder might cause nephrolithiasis. Instead, chronic hyperparathyroidism secondary to renal failure and dialysis might cause bone pain related to bone remodeling process, fibrous degeneration, and formation of cysts and nodules of fibrosis.

Clinical presentation depends on grade and time of onset. Most common symptoms are general malaise, thirst, lethargy, and constipation often associated with abdominal pain. Renal symptoms and signs such as polyuria, polydipsia, nycturia, nephrolithiasis, and rarely renal failure and nephrocalcinosis should be also considered.

Neuromuscular disorders, starting from muscles weakness, emotional instability, and confusion, until development of delirium, psychosis, stupor, and coma, could be observed in acute or severe hypercalcemia (serum calcium levels $>12 \mathrm{mg} / \mathrm{dL}$ ). Furthermore, hypercalcemia might cause cardiac arrhythmias. The most common electrocardiographic changes are absent or shortened ST segment, shortened QT interval, widened QRS complex, enlarged T wave, and prolonged PR interval. Rarely, it might cause branch block and arrhythmias until to cardiac arrest in the case of serum calcium levels over $15 \mathrm{mg} / \mathrm{dL}^{[88]}$.

Renal function and immunoreactive parathyroid hormone analysis are recommended for a complete diagnostic classification that allows making differential diagnosis and to consider potential serious conditions (cardiac arrhythmias).

Electrocardiography should also be performed in order to avoid presence of cardiac alterations ${ }^{[95]}$.

Generally, primary hyperparathyroidism is usually characterized by hypercalcemia (with high ionized free serum calcium levels), hypophosphatemia, PTH being inappropriately high (e.g., no hypocalcemia), and excessive bone turnover.

Differential diagnosis between primary and secondary hyperparathyroidism could be difficult in the case of renal failure, although hyperphosphatemia is often linked to secondary hyperparathyroidism and normal or low phosphorus levels are indicative of primary hyperparathyroidism ${ }^{[96]}$.

Furthermore, in the presence of secondary hyperparathyroidism, radiographic examination should be useful to detect bone cysts presence and bone reabsorption.

When hyperparathyroidism has been excluded, a serum calcium level above $12 \mathrm{mg} / \mathrm{dL}$ is suspicious of malignancies, mostly when associated with hypophosphatemia, hypoalbuminemia, and lower or undetectable PTH level. PTHrP is a peptide that shows homology with the N-terminal portion of PTH, mimicking the action. It can be produced from breast, lung, and kidney cancer cells. When possible, the individuation of PTHrP is useful for reach diagnosis of paraneoplastic hypercalcemia ${ }^{[88]}$. 


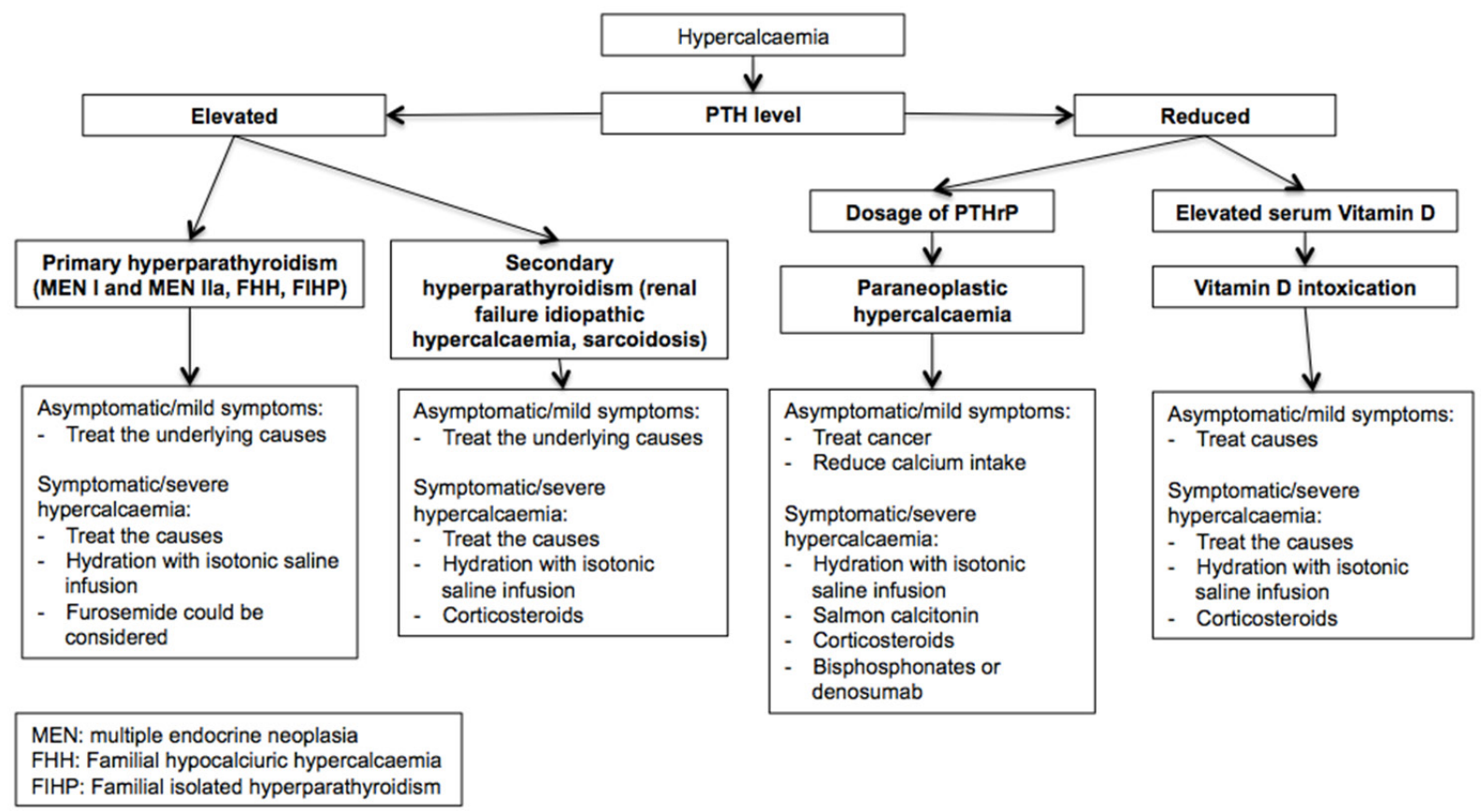

Figure 4. Algorithm of hypercalcemia management ${ }^{[48,88,94-104]}$. To treat hypercalcemia, a correct diagnostic framework is essential, which is based on the parathyroid dosage to distinguish between hyperparathyroidism and other causes. In the case of low blood PTH concentrations, the dosage of PTHrP is useful to exclude paraneoplastic hypercalcemia and vitamin D intoxication. PTH: parathyroid hormone; PTHrP: parathyroid hormone-related protein; MEN: multiple endocrine neoplasia; FHH: familial hypocalciuric hypercalcaemia; FIHP: familial isolated hyperparathyroidism

Treatment depends on clinical manifestation, grade of hypercalcemia, and underlying cause, which should be correct whenever possible [Figure 4]. In the case of mild symptoms, serum calcium levels are below $11.5 \mathrm{mg} / \mathrm{dL}$, which could sufficiently remove the cause of hypercalcemia.

In the case of severe hypercalcemia (total serum calcium over $15 \mathrm{mg} / \mathrm{dL}$ ) or severe symptoms or signs, a treatment aimed to reduce serum calcium levels is recommended, in order to restore adequate intravascular volume and to improve glomerular filtration rate ${ }^{[96]}$. Since hypercalcemia induces polyuria, most patients are dehydrated. Therefore, intravenous isotonic saline solution $(\mathrm{NaCl} 0.9 \%)$ should be administered with an infusion rate of $100 / 120 \mathrm{~mL} / \mathrm{h}$, in order to obtain a urine output of $100-150 \mathrm{~mL} / \mathrm{h}$ and a reduction of serum calcium concentration ${ }^{[97]}$. Two to three liters of isotonic saline solution/day with a close monitoring of serum electrolyte levels and urinary volume is recommended ${ }^{[98]}$. In patients with edematogenic syndromes (e.g., congestive heart failure) or anuria isotonic solution should be administered with caution in order to avoid fluid overload. However, only $30 \%$ of patients reach normocalcemia with fluids alone. Loop diuretics (e.g., furosemide) might be considered mostly in patients with edematogenic syndromes, in whom it is required to improve diuresis. The use of furosemide should be limited in dehydrated patients or in patients presenting other electrolyte abnormalities (magnesium and, potassium) ${ }^{[99]}$.

In patients with malignant hypercalcemia, salmon calcitonin administration (4-8 IU/kg s.c. or i.m. every $12 \mathrm{~h}$ ) was demonstrated to control serum calcium levels (estimated a maximal serum calcium drop of $2 \mathrm{mg} / \mathrm{dL}$ in $4 \mathrm{~h}$ after administration), and it can be used also in patents with renal injuries, in which intravenous saline is not recommended ${ }^{[100]}$. Furthermore, calcitonin is more efficacious and quicker than bisphosphonates in normalizing calcemia and it can be used with bisphosphonates or in the case of bisphosphonates' resistance. However, due to the risk of tachyphylaxis, the duration of treatment with calcitonin should not exceed $48 \mathrm{~h}^{[101]}$. 
The addition of corticosteroids (e.g., 20-40 mg of prednisone/day) is useful to control malignant hypercalcemia especially due to hematological tumors, through an increased renal calcium excretion and inhibition of bone reabsorption. However, since fewer than $50 \%$ of patients with malignant hypercalcemia respond to glucocorticoids after several days, in clinical practice. an alternative treatment is usually preferred. Corticosteroids are also use for the treatment of vitamin D intoxication, idiopathic hypercalcemia, and sarcoidosis ${ }^{[102]}$.

Finally, bisphosphonates, such as ibandronate, pamidronate, and mostly zoledronic acid, have been shown to be effective in reducing serum calcium in approximately $12 \mathrm{~h}^{[103]}$.

Recent evidence demonstrates the activity of denosumab in control malignant hypercalcemia, especially in patients with persistent hypercalcemia despite bisphosphonates. Furthermore, it could also be used in patients with reduced renal function ${ }^{[104]}$.

\section{POTASSIUM}

Potassium is the second most abundant cation in the human organism. It is the main intracellular cation; in fact, only $2 \%-5 \%$ of total body potassium is restrained in extracellular fluids, including blood. Normal serum potassium concentration ranges between 3.5 and $5.0 \mathrm{mEq} / \mathrm{L}^{[105]}$. The maintenance of this concentration is crucial for several physiological processes (maintenance of cellular membrane potential, cellular volume, and action potentials' transmission in nerve cells ${ }^{[105]}$. Many mechanisms act for preserving potassium homeostasis: oral intake, renal elimination, and balance between intracellular and extracellular concentration.

Renal active excretion of potassium in cortical collecting ducts is regulated by aldosterone, through the modification of the epithelial sodium channel into the open configuration and the increase of the number of epithelial sodium channel. This modification favors sodium reabsorption and increases potassium secretion $^{[106]}$.

Potassium transit among intracellular and extracellular fluid compartments depends on $\mathrm{Na}^{+}-\mathrm{K}^{+}$-ATPase, a membrane pump ubiquitous in all cells ${ }^{[107]}$. This ionic channel creates a concentration gradient across cell membrane, maintaining the potential of cell membrane. Several factors influence the transit of potassium through cell membrane: blood $\mathrm{pH}$, in particular, alkalosis induces the potassium's input from extracellular to intracellular fluid compartments, while acidosis causes the leak of potassium from cells. Furthermore, insulin and b-adrenergic catecholamines favor potassium's input into cells ${ }^{[108]}$.

Several potassium channels are involved in cancer proliferation. Potassium channels $(\mathrm{KCN})$ are a large group of proteins involved in potassium transfer. In breast cancer, KCNMA1, KCNJ3, KCNN4, and KCNK9 are associated with estrogen receptor's expression and brain and lymph-node metastasis ${ }^{[109]}$. In prostate cancer, several potassium channels are involved. In particular, KCNMA1 represents a promising diagnostic biomarker of prostate cancer. In fact, it is over-expressed in cancer cells with Gleason score of 5-6, and in hormone sensitive phase. KCNK2 seems to be involved in the regulation of cell proliferation ${ }^{[110]}$. KCNQ1, a pore $\mathrm{K}^{+}$channels, is over-expressed in more than $35 \%$ of lung tumors and it favors tumor development, cell proliferation and migration, and resistance to hypoxia ${ }^{[111]}$. Voltage-gated $\mathrm{K}^{+}$channels seem to have an important role in colorectal cancer. In particular, over-expression of $\mathrm{KCNH} 2$ regulates cell invasion, giving an invasive phenotype to the tumor, and it represents a negative prognostic factor in early stages when associated with the absence of Glut-1. It also seems to confer different chemosensitivity to different drugs; in particular, cells with over-expression of $\mathrm{KCNH} 2$ are inhibited by paclitaxel, vincristine, and hydroxy-camptothecin, while they seem to have resistance to doxorubin. The clinical implication it due to 
the influence of $\mathrm{KCNH} 2$ in modulating VEGF-A secretion ${ }^{[112]}$. Overexpression of $\mathrm{KCNH} 2$ has been also demonstrated to be associated with poorer prognosis in squamous-cell carcinoma of esophagus ${ }^{[113]}$. Overexpression of $\mathrm{KCNH} 2$ seems to also have a role in pancreatic cancer. In particular, it is involved in EGFR pathway, conferring an aggressive behavior and poorer prognosis ${ }^{[114]}$. $\mathrm{KCNH} 2$ has also been investigated in gastric cancer. In particular, it has been demonstrated to be negatively correlated with grading, stage of disease, venous invasion, and shorter survival ${ }^{[115]}$. Otherwise, it has been investigated in surgical samples of patients undergoing radical tumor resection and it seem to correlate with Lauren's intestinal type, fundus localization, low grading, and early stages (TNM I and II) ${ }^{[116]}$. Furthermore, it has been demonstrated to modulate VEGF-A secretion and cisplatin-induced apoptosis ${ }^{[117]}$.

\section{Hypokalemia}

Definition and clinical implications

Hypokalemia is defined as a low serum potassium concentration $(<3.5 \mathrm{mEq} / \mathrm{L})$. Severe hypokalemia is defined as a potassium level lower than $2.5 \mathrm{mEq} / \mathrm{L}$, representing a potential life-threatening disorder ${ }^{[118]}$.

\section{Causes}

Hypokalemia is a common electrolyte disorder in cancer patients. Several causes might induce hypokalemia in cancer patients ${ }^{[108]}$ :

(1) Cancer: several conditions related to cancer might induce a reduced potassium intake (malnutrition, anorexia, and malabsorption due to cancer bowel infiltration or bowel obstruction). Some neuroendocrine tumors might cause hypokalemia through secretive diarrhea, favoring potassium losses. Other tumors induce renal potassium losses through the production of hormones such as adrenocorticotropic hormone (ACTH), cortisol, and mineralocorticoids, or through kidney damage, such as multiple myeloma.

(2) Cancer treatment: chemotherapeutic agents, target therapies and immunotherapies might cause hypokalemia secondary to diarrhea or vomiting.

(3) Concomitant drugs: thiazide diuretics, insulin, granulocyte growth factors, beta-2 agonists, and glucocorticoids might cause hypokalemia.

(4) Concomitant diseases: endocrine dysfunctions causing excess glucocorticoids or mineralocorticoids, toxic epidermal necrolysis, and inflammatory bowel diseases might cause hypokalemia.

Causes of hypokalemia might be resumed substantially in three mechanisms: an inadequate potassium intake, redistribution of potassium among intra- and extracellular compartments, and potassium losses [Table 5].

In cancer patients, inadequate intake is often related to malnutrition and anorexia due to drugs and/or tumor condition.

The passage of potassium into the intracellular compartment might depend on many mechanisms: uptake of potassium by tumor cells, alkalosis, hypothermia, and drugs. For example, granulocyte growth factors, often employed in cancer patients, provoke an acute hematopoietic cell formation, favoring rapid potassium intake by the new cells ${ }^{[119]}$. Hypokalemia is similarly induced by rapid cell proliferation in acute leukemia ${ }^{[120]}$.

Potassium losses can be classified into renal and non-renal losses. The most common extra-renal losses are gastrointestinal losses due to drugs or cancer-induced diarrhea and vomiting, infections, radiation enteritis, and type of tumors (villous adenoma and neuroendocrine neoplasms) ${ }^{[121]}$. In particular, neuroendocrine neoplasms, although rare, are represented with the carcinoid syndrome characterized by serotonin and 
Table 5. Causes of hypokalemia

\begin{tabular}{|c|c|}
\hline Causes of hypokalemia & \\
\hline Reduced potassium intake & $\begin{array}{l}\text { Malnutrition, anorexia, refeeding syndrome } \\
\text { Gastrointestinal injuries } \\
\text { Vomit (caused by anticancer therapies, intestinal obstruction, etc.) } \\
\text { Diarrhea (caused by anticancer therapies, cancer, surgery) }\end{array}$ \\
\hline $\begin{array}{l}\text { Redistribution of the potassium } \\
\text { into intracellular compartment }\end{array}$ & $\begin{array}{l}\text { Drugs (catecholamine, nasal decongestants, insulin, granulocyte growth factors, beta- } 2 \text { agonists, } \\
\text { barium intoxication, theophylline, bicarbonate, verapamil) } \\
\text { Alkalosis } \\
\text { Hypothermia }\end{array}$ \\
\hline Increased potassium losses & $\begin{array}{l}\text { Non-renal losses: } \\
\text { Losses (diarrhea, vomiting, fistula, laxative abuse, villous adenoma) } \\
\text { Profuse sweating } \\
\text { Extended burns } \\
\text { Toxic epidermal necrolysis } \\
\text { Renal losses: } \\
\text { Metabolic alkalosis } \\
\text { Use of diuretics } \\
\text { Osmotic diuresis } \\
\text { Renal tubular diseases (tubular acidosis, Liddle syndrome) } \\
\text { Endocrine dysfunctions (excess of glucocorticoids or mineralocorticoids, primary hyperaldosteronism } \\
\text { due to adenoma or adrenal carcinoma, renin-secreting neoplasms, ectopic secretion of ACTH) } \\
\text { Concomitant electrolyte disorders (hypercalcemia, hypomagnesemia) } \\
\text { Drugs (amphotericin B, cisplatin, ifosfamide, glucocorticoids, anti-EGFR agents, mTOR inhibitors, } \\
\text { eribulin, abiraterone) }\end{array}$ \\
\hline
\end{tabular}

ACTH: adrenocorticotropic hormone; EGFR: endothelial growth factor receptor

kallikrein hypersecretion inducing flushing, severe secretory diarrhea with cramps and hypokalemia, tachycardia, hypotension until heart failure, and bronchial constriction ${ }^{[122]}$. Another rare syndrome due to tumor hypersecretion of vasoactive intestinal polypeptide induces important watery diarrhea with hypokalemia and achlorhydria ${ }^{[123]}$.

Renal losses have several potential causes. Endocrine disorders should be considered in cancer patients. For example, Cushing syndrome can be due in rare cases to ACTH-producing tumors, especially in patients with small-cell lung cancer, medullary thyroid carcinoma, islet cell adenoma or carcinoma, pheochromocytoma, and ganglioneuroma, inducing an excessive production of cortisol able to blind mineralocorticoid receptors inducing hypokalemia ${ }^{[124]}$. Another rare cause is primary aldosteronism, due to the excessive and autonomous secretion of aldosterone by adrenal adenomas or carcinoma. This syndrome is characterized by polydipsia, polyuria, resistant hypertension, and severe hypokalemia ${ }^{[125]}$.

Furthermore, a common cause of potassium renal losses in cancer patients is drug-related tubular toxicity. Several chemotherapeutic agents, target therapies, and immunotherapeutic drugs [Table 5] might induce renal injury associated to hypokalemia. Renal function should be evaluated before drug administration to avoid further renal damage ${ }^{[126]}$. Concomitant therapies such as thiazide diuretics and glucocorticoids can favor potassium renal losses.

Finally, some kinds of tumor induce renal damage. For example, patients with multiple myeloma producing Bence-Jones proteins develop a progressive renal injury leading to hypomagnesemia and hypokalemia. Acute myeloid leukemia, through secretion of lysozyme, induces renal tubular damage ${ }^{[127]}$.

In hematological patients, especially in those with marked leukocytosis (e.g., in acute myeloid leukemia), hypokalemia can be confused with pseudo-hypokalemia, due to potassium intake in the stored blood sample before the laboratory analysis ${ }^{[128]}$.

\section{Management}

Clinical presentation depends on severity of hypokalemia. Patients are often asymptomatic, especially those with mild hypokalemia ${ }^{[129]}$. Symptoms and sign of hypokalemia are non-specific and due to 


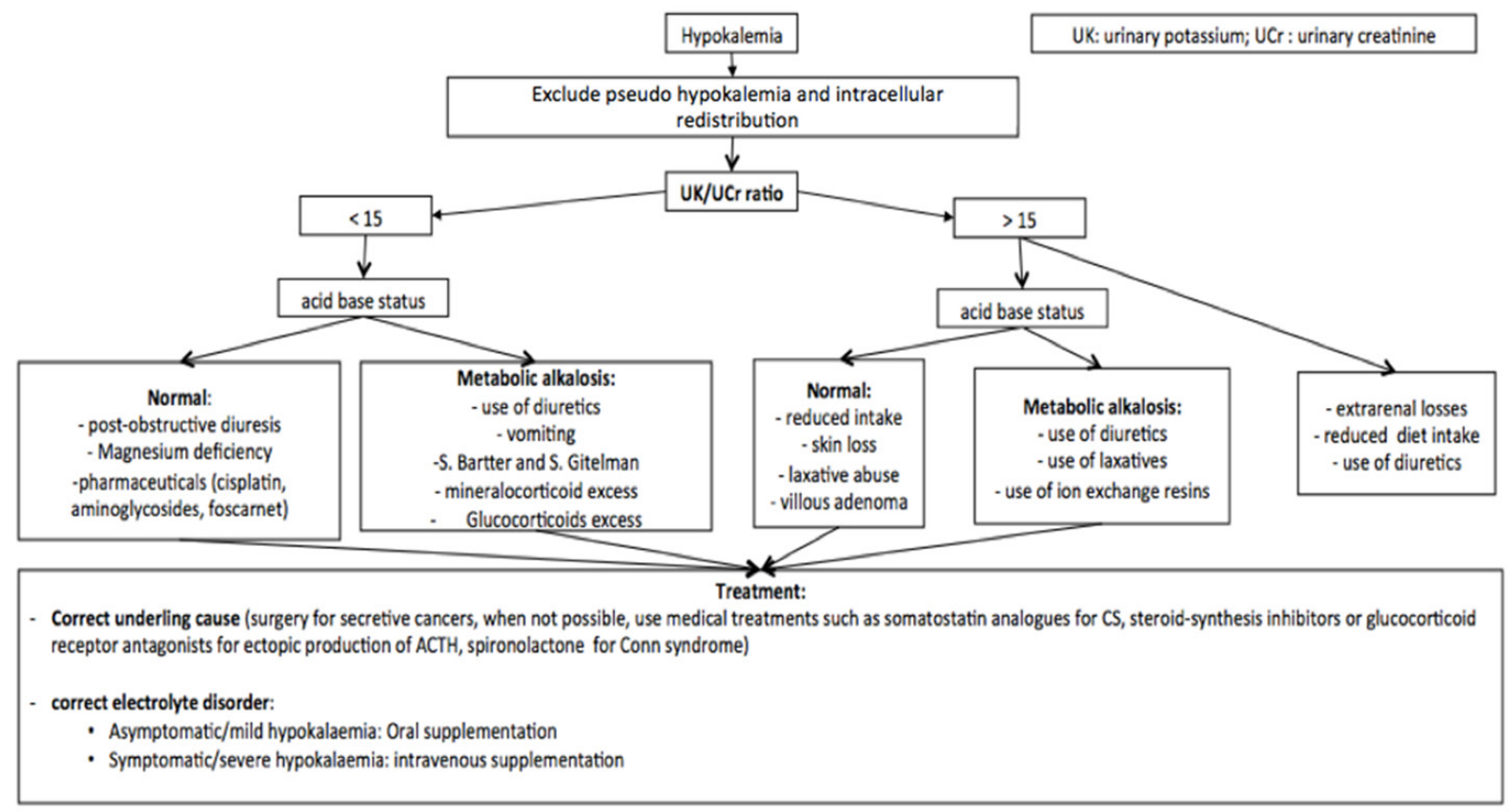

Figure 5. Algorithm of hypokalemia management ${ }^{[48,129-139]}$. In the case of hypokalemia, it is useful to consider oral or intravenous supplementation based on the degree and symptoms. It is always useful to associate the identification and correction of the underlying cause. For a correct differential diagnosis, it is essential to evaluate UK and UCr. UK: urinary potassium; Ucr: urinary creatinine

muscular, neurological, or cardiac dysfunction. The most common clinical manifestation is characterized by weakness, fatigue, myalgia, muscle cramps, and constipation. In the case of moderate or severe hypokalemia, neurological and psychiatric symptoms (e.g., psychosis, delirium, hallucinations, and depression), or cardiac signs (bradycardia) until acute respiratory failure with cardiovascular collapse, secondary to muscle paralysis, might occur. In particular, cardiac arrhythmias represent life-threatening complications requiring immediate diagnosis and adequate treatment. Therefore, ECG monitoring should be performed in patients with hypokalemia (typical alterations are inverted $\mathrm{T}$ waves, appearance of $\mathrm{U}$ wave, ST depression, and enlarged PR interval) ${ }^{[130]}$.

Diagnosis of hypokalemia is based on detection of low serum potassium levels. For a correct management of hypokalemia, it is important to understand the underlying causes. For a correct differential diagnosis, it is important investigate the patient's medical history, evaluating the concomitant therapies and clinical conditions that might cause potassium losses or intracellular redistribution (insulin, diuretics, nephrotoxic agents, anticancer agents, diarrhea, and vomiting). Presence of pseudo-hypokalemia should be excluded in patients with marked leukocytosis.

Furthermore, other laboratory exams should be performed for a correct differential diagnosis. Blood sugar, acid-base balance, creatinine, magnesium levels, and urine electrolytes concentration should be evaluated [Figure 5] ${ }^{[131]}$. In particular, 24-h renal potassium concentration is useful to establish renal or extra-renal potassium losses.

When urinary potassium is $>30 \mathrm{mEq} / \mathrm{L}$ there is a renal potassium loss, while a urinary potassium concentration of $<25 \mathrm{mEq} / \mathrm{L}$ might be related to an extra-renal potassium loss. Another useful evaluation to distinguish between renal and extra-renal potassium losses is the urinary potassium concentration and urinary creatinine concentration ratio. Values $>15$ are suggestive for renal potassium losses ${ }^{[131]}$. 
The treatment of hypokalemia depends on symptoms and their severity. It is focused on preventing lifethreatening complications and removing the underlying cause [Figure 5].

In patients with mild or moderate hypokalemia (serum potassium levels of 3.0-3.5 mEq/L), potassium oral supplementation should be preferred to intravenous, in order to avoid an iatrogenic hyperkalemia. A daily dose of $60-80 \mathrm{mEq}$ of potassium chloride is recommended. However, it is important to monitor serum potassium concentration in order to adjust treatment doses accordingly. In the case of chronic hypokalemia refractory to oral supplementation, the addition of potassium-sparing diuretics (amiloride and spironolactone) should be considered ${ }^{[132]}$.

In asymptomatic patients with severe hypokalemia (serum potassium level of $<3.0 \mathrm{mEq} / \mathrm{L}$ ), an oral potassium supplementation with potassium chloride $40 \mathrm{mEq}$ every 3-4 h should be considered ${ }^{[133]}$. Otherwise, in symptomatic patients with a life-threatening complication, or in patients unable to take oral drugs, intravenous potassium $(10-20 \mathrm{mEq} / \mathrm{h}$, able to increase serum potassium level an average of $0.25 \mathrm{mEq} / \mathrm{h}$ ) is recommended ${ }^{[134]}$. Continuous ECG monitoring is recommended in patients with arrhythmias, digitalis toxicity, and history of cardiac ischemia. In patients with renal failure, the doses should be reduced and serum potassium level monitored frequently. Refractory hypokalemia might depend on the presence of concomitant electrolyte disorders, such as hypomagnesemia, which should be investigated and treated when present ${ }^{[135]}$.

When hypokalemia is secondary to tumor activity, treating the cancer is necessary, in addition to symptomatic therapy for hypokalemia, in order to prevent the recurrence of symptoms.

Patients with carcinoid syndrome should receive somatostatin analog in order to inhibiting hormonal hyper-secretion and improve symptoms ${ }^{[136]}$. When hypokalemia depends on primary aldosteronism, unilateral adrenalectomy is preferred to mineralocorticoid receptor antagonists ${ }^{[137]}$.

In the case of ectopic ACTH secretion, a complete resection of the tumor should be preferred, when possible. Other treatment options, such as steroid-synthesis inhibitors (metyrapone, mitotane, trilostane, ketoconazole, and aminoglutethimide) and glucocorticoid receptor antagonists (mifepristone), are available to control severe hypercortisolemia ${ }^{[138]}$. In patients with severe (Grades 2-3) diarrhea due to anticancer drugs or radiotherapy, a symptomatic treatment with probiotics, loperamide, and in refractory cases octreotide should be administered in order to prevent hypokalemia ${ }^{[139]}$.

\section{Hyperkalemia}

\section{Definition and clinical implications}

Hyperkalemia is defined as an increased serum potassium concentration (> $5.5 \mathrm{mEq} / \mathrm{L})$. According to potassium level, three different grades of severity are described: mild hyperkalemia (5.1-6.0 mEq/L), moderate hyperkalemia (6.1-7.0 $\mathrm{mEq} / \mathrm{L})$, and severe hyperkalemia $(>7.0 \mathrm{mEq} / \mathrm{L})$, which represents a lifethreatening condition ${ }^{[140]}$.

\section{Causes}

Several causes might induce hypokalemia in cancer patients ${ }^{[108]}$ :

(1) Cancer: several conditions related to cancer might induce hyperkalemia. Tumors with high proliferative index such as leukemia and small-cell lung carcinomas can result in lysis syndrome after specific anticancer treatment, inducing hyperkalemia.

(2) Cancer treatment: chemotherapeutic agents, such as platinum derivatives, might cause renal injury, which can lead to hyperkalemia. 
Table 6. Causes of hyperkalemia

\begin{tabular}{ll}
\hline Causes of hyperkalemia & \\
\hline Increased intake & latrogenic (excessive potassium infusion, parenteral nutrition, etc.) \\
Redistribution into extracellular & Massive tissue catabolism (hemolysis, sepsis, diffuse trauma, rhabdomyolysis, \\
compartment & chemotherapies, lysis syndrome) \\
& Drugs (beta-blockers, arginine, digital) \\
& Metabolic acidosis \\
& Insulin deficiency and hyperglycemia \\
& Severe muscular exercise \\
& Pseudo-hyperkalemia (in vitro hemolysis, leukocytosis, thrombocytosis) \\
Reduction of renal excretion of potassium & Renal injuries: \\
& Acute or chronic renal failure \\
& Depletion of effective circulating volume \\
& Tubulopathies \\
& Selective alteration of potassium excretion (acute transplant rejection, lupus nephritis, \\
& cyclosporine, analgesic nephropathy, lead poisoning) \\
& Nephrotoxic drugs (cisplatin, ifosphamide, mitomycin C, gemcitabine, methotrexate, \\
& bisphosphonates, interferon, somatostatin analogs) \\
& Corticosurrenal insufficiency: \\
& Iporeninemic hypoaldosteronism (diabetic nephropathy, chronic interstitial nephritis, drug \\
& nephropathy) \\
& Primitive hypoaldosteronism (M. Addison) \\
& Use of potassium-sparing diuretics \\
&
\end{tabular}

(3) Concomitant drugs: diuretics, potassium-sparing diuretics, angiotensin-converting enzyme, inhibitors, and NSAIDs might induce hypokalemia.

(4) Concomitant diseases: renal failure, diabetes mellitus, sepsis, and parenteral nutrition might induce hypokalemia.

However, causes of hyperkalemia might be resumed in different mechanisms, such as excessive intake, redistribution into extracellular compartment, or abnormal renal elimination, that might depend on aldosterone deficiency or on renal parenchyma damage [Table 6].

Rarely, hyperkalemia depends only on increased potassium intake, and it is often associated with other risk factors: renal failure, diabetes mellitus, and concomitant medications that inhibit potassium excretion (e.g., potassium-sparing diuretics, angiotensin-converting enzyme inhibitors, and NSAIDs). Furthermore, in cancer patients, parenteral nutrition rich in potassium might induce to life-threatening hyperkalemia ${ }^{[141]}$.

Tumor lysis syndrome (TLS) represents an important cause of acute hyperkalemia in cancer patients. It is a rare but serious oncological emergency characterized by hyperuricemia, hyperkalemia, hyperphosphatemia, hypocalcemia, and azotemia. It usually appears 48-72 h after the commencement of anticancer-therapy (chemotherapy, radiotherapy, and radiofrequency ablation) as a consequence of massive cell necrosis and acute release of intracellular factors into the systemic circulation ${ }^{[142]}$. In particular, elevated uric acid and calcium phosphate release tend to precipitate into renal tubules, causing local damage with glomerular filtration rate reduction until acute kidney injury (AKI). AKI worsens metabolic disorders and hyperkalemia, which might induce severe cardiac arrhythmias until death; low serum calcium levels and acidosis may exacerbate this risk ${ }^{[143]}$. In high-grade hematologic malignancies and childhood cancers, it might also occur spontaneously ${ }^{[144]}$.

Several predisposing factors to tumor lysis syndrome were detected, such as elevated tumor burden, rapidgrowing neoplasms, high tumor sensibility to anti-cancer treatment, concomitant renal failure, elevated lactate dehydrogenase serum level, hyperuricemia, and hyperazotemia. These factors should be investigated before starting treatment, in order to set up a preventive therapy ${ }^{[145]}$. 


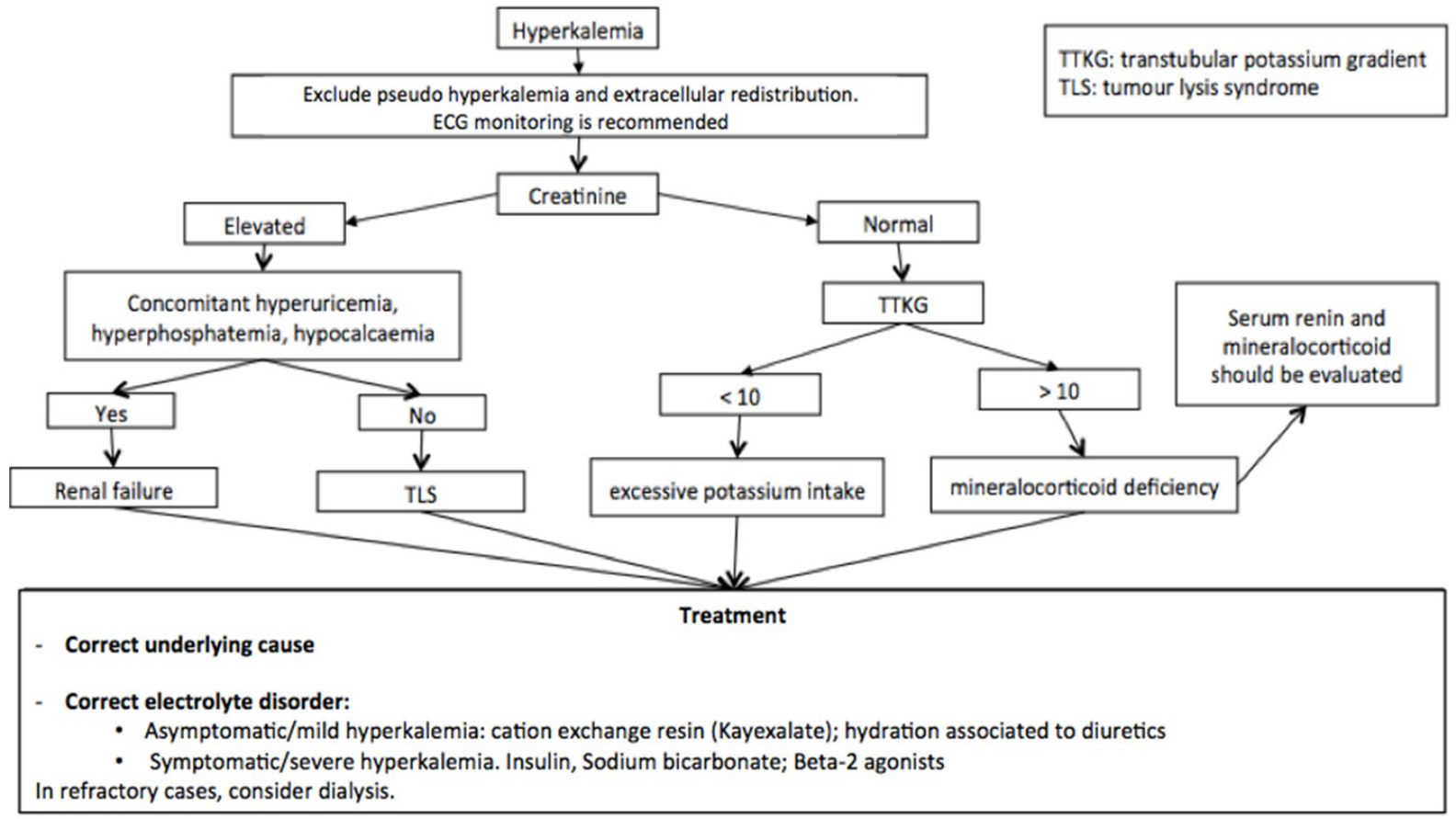

Figure 6. Algorithm of hyperkalemia management ${ }^{[48,149-154]}$. In the case of hyperkalemia, the treatment is based on the degree and reported symptoms. When patients are symptomatic for hyperkalemia, insulin, beta-2 agonist, and sodium bicarbonate should be considered. It is always useful to associate the identification and correction of the underlying cause. For a correct differential diagnosis, it is necessary to evaluate renal function through blood creatinine level. If elevated, evaluate uricemia, calcemia, and phosphatemia to distinguish between renal failure and tumor lysis syndrome. TLS: tumor lysis syndrome; TTKG: transtubular potassium gradient

Adrenal insufficiency secondary to metastasis involving both adrenal glands might cause hyperkalemia in cancer patients, especially with advanced lung and breast cancer or lymphomas. However, despite the high frequency of adrenal metastasis (40\%-60\% of patients), adrenal insufficiency is rarely described, thanks to concomitant administration of corticosteroids ${ }^{[146]}$. Finally, in the case of elevated leukocytosis or thrombocytosis, hyperkalemia should be distinguished from pseudo-hyperkalemia, due cellular potassium escape after the blood sample is taken ${ }^{[147]}$.

\section{Management}

Diagnosis of hyperkalemia occurs with the detection of elevated serum potassium concentration. The diagnosis is often an incidental laboratory finding, as patients are often asymptomatic, especially in the case of plasma potassium concentration of $<5.5 \mathrm{mEq} / \mathrm{L}$. When present, symptoms and signs are related to altered cellular resting membrane potential, causing muscle, neurological and cardiac dysfunctions, until life-threatening cardiac arrhythmias. Patients might experience, according to hyperkalemia grade, fatigue and weakness, fasciculation, cramps, and parenthesis, as well as muscular paralysis and palpitations in serious cases. Sometimes, the only signs of hyperkalemia are electrocardiographic specific alterations or cardiac arrhythmias such as pointed T-waves, decrease or absence of P waves, prolonged PR interval, enlarged QRS complex, reduced QT interval, ventricular fibrillation, or asystole ${ }^{[148]}$.

For a correct differential diagnosis, clinical history evaluating potassium intake and concomitant medications should be collected [Figure 6]. Furthermore, other laboratory exams should be performed: complete blood count, urinary potassium, sodium and osmolality, transtubular potassium gradient (TTKG), renal function, lactate dehydrogenase, and uricemia. Elevated serum creatinine and urea associated with hyperkalemia are suspicious for renal failure. Hyperkalemia, concomitant to the presence of hyperuricemia, hyperphosphatemia, and hypocalcemia, might be suggestive of TLS. In the case of TTKG > 10, hyperkalemia might depend on excessive potassium intake. Instead, a TTKG $<10$ is generally due to a mineralocorticoid 
insufficiency and serum concentrations of renin and mineralocorticoid should be evaluated to confirm the $\operatorname{diagnosis}^{[149]}$.

For a correct management of cancer patients with hyperkalemia, it is important to consider presence of ECG alteration, symptoms, and degree of hyperkalemia.

Hyperkalemia treatment requires first to eliminate all potassium exogenous sources and, when possible, discontinue treatment with drugs favoring hyperkalemia [Figure 6].

Furthermore, it is important to counteract cardiac effects of hyperkalemia. In the case of enlargement of QRS complex, intravenous infusion of calcium (e.g., $1 \mathrm{fl}$ calcium gluconate $10 \mathrm{~mL}$ ) and electrocardiographic monitoring are required.

In the case of severe hyperkalemia and electrocardiographic alterations, immediate treatment should be set up. To obtain a rapid reduction of serum potassium level, the administration of medications able to bring potassium in intracellular compartment should be performed ${ }^{[150]}$. Several treatment options can be considered:

- Insulin (e.g., 10 units of fast insulin associated to $500 \mathrm{~mL}$ of glucose solution at $10 \%$ or $250 \mathrm{~mL}$ of glucose solution infused in 30-60 min).

- Sodium bicarbonate (e.g., Sodium bicarbonate $1 \mathrm{mEq} / \mathrm{kg}$ in 10-20 min), which should be avoided in patients with heart or renal failure, because it might worsen fluid retention.

- Beta-2 agonists (e.g., 10-20 mg salbutamol to inhale in $10 \mathrm{~min}$ ), which should be avoided in patients with ischemic cardiomyopathy or cardiac arrhythmias.

Although these treatment options are effective in rapidly correcting hyperkalemia, the redistribution of potassium into the intracellular compartment is temporary. Furthermore, sodium bicarbonate and beta- 2 agonists should be used as adjuvant treatments, in combination with other therapies ${ }^{[150]}$.

Patients with moderate and asymptomatic hyperkalemia do not require an immediate serum potassium reduction and can be treated with medications that remove potassium excess but require several hours ${ }^{[151]}$. Several treatment options can be considered. Cation exchange resins (Kayexalate) should be preferred. However, due to high sodium content, they have to be used with caution in presence of heart or renal failure, to avoid fluid retention.

Abundant intravenous hydration associated with diuretics (furosemide 40-80 $\mathrm{mg}$ ) can be considered a valid treatment option; however, it should be avoided in patients with heart failure for fluid overload risk. Furthermore, diuretics have been demonstrated to control serum potassium level only in chronic hyperkalemia, and they should be reserved only for the management of these forms. Dialysis can be considered in the case of renal failure when resins and diuretics fail ${ }^{[152]}$.

In patients with severe hyperkalemia, plasma potassium levels and ECG should be frequently monitored during treatment (every 1-6 h) until symptoms' resolution, followed by monitoring every $4-12 \mathrm{~h}$ until normokalemia achievement ${ }^{[153]}$.

\section{MAGNESIUM}

Magnesium is an important intracellular cation, second to potassium for prevalence. It acts as an essential cofactor for several intracellular enzymes involved in cells replication and energy metabolism processes, including phosphate transfer. Furthermore, it has a crucial role in muscular contractility and neuronal transmission ${ }^{[154]}$. 
Almost the complete amount (about 99\%) of magnesium is placed in the intracellular compartment: about $50 \%-60 \%$ is in bone and $38 \%$ in soft tissues, while only $1 \%$ of total body magnesium is extracellular. Normal serum magnesium concentration is between 1.5 and $1.9 \mathrm{mEq} / \mathrm{L}(1.7-2.2 \mathrm{mg} / \mathrm{dL})$. Dietary magnesium absorption takes place in intestinal tract, and it is negatively influenced by high protein, phosphate, and fat. Magnesium elimination is mainly controlled by kidney. Several factors (hormonal: PTH, calcitonin, glucagon, and vasopressin; and non-hormonal: acid-base balance, potassium reduction, and magnesium plasma concentration) are involved in renal elimination ${ }^{[15]}$.

\section{Hypomagnesemia}

\section{Definition and clinical implications}

Hypomagnesemia is an electrolyte disorder characterized by reduced magnesium serum level $(<1.5 \mathrm{mEq} / \mathrm{L})$. Serum magnesium concentration lower than $1 \mathrm{mg} / \mathrm{dL}$ is defined as severe hypomagnesemia. It occurs frequently $(7 \%-12 \%)$ in hospitalized patients, and it is correlated to increased risk of death ${ }^{[156]}$.

\section{Causes}

Hypomagnesemia in cancer patients might result from different causes:

(1) Cancer: several conditions related to cancer might induce hypomagnesemia. Anorexia, malnutrition, vomiting, intestinal injury, intestinal drainage/fistulae, diarrhea, and malabsorption syndrome are frequent conditions in cancer patients inducing reduced magnesium intake.

(2) Cancer treatment: several drugs commonly used in cancer patients induce kidney damage and secondary hypomagnesemia. Cisplatin might induce hypomagnesemia through distal renal tubular damage, and it persists after treatment discontinuation. Therefore, intravenous supplementation of magnesium is indicated to prevent hypomagnesemia and decrease risk of nephrotoxicity ${ }^{[157]}$. Hypomagnesemia was also described in patients receiving EGFR inhibitors with an incidence of $34 \%$ in patients treated with monoclonal anti-EGFR antibodies. In fact, EGFR activation is crucial for magnesium renal reabsorption through TRPM-6 channel ${ }^{[158]}$.

(3) Concomitant drugs: diuretics, antibiotics beta-adrenergic agonists, foscarnet, and amphotericin B might induce hypomagnesemia.

(4) Concomitant diseases: hyperparathyroidism, hyperthyroidism, diabetes mellitus, dialysis, renal failure, and hereditary disorders (e.g., Bartter's syndrome and Gitelman's syndrome) might induce hypomagnesemia.

Three main mechanisms are involved: reduced intake, redistribution into intracellular compartment, and increased renal losses [Table 7].

The most common mechanism inducing hypomagnesemia is renal losses. However, reduced magnesium intake is also frequent in cancer patients, mainly due to altered absorption secondary to diarrhea, malabsorption syndromes, and extensive bowel resection, while rarely due to severe malnutrition.

\section{Management}

Treatment of hypomagnesemia depends on clinical manifestation and severity, and it should be focused on hypomagnesemia correction and causes removal.

Patients with hypomagnesemia are usually asymptomatic, until magnesium concentration falls below $1.2 \mathrm{mg} / \mathrm{dL}$, although symptoms usually do not correlate with serum magnesium levels ${ }^{[159]}$.

The earliest manifestations of magnesium deficiency are usually non-specific neuromuscular and neuropsychiatric alterations such as weakness and muscle cramps. Severe hypomagnesemia might cause 
Table 7. Causes of hypomagnesemia

\begin{tabular}{|c|c|}
\hline Causes of hypomagnesemia & \\
\hline Reduced intake & $\begin{array}{l}\text { Insufficient introit (anorexia, malnutrition, vomiting) } \\
\text { Altered intestinal absorption (intestinal injury, intestinal drainage/fistulae, diarrhea, malabsorption } \\
\text { syndrome) } \\
\text { Alcoholism }\end{array}$ \\
\hline $\begin{array}{l}\text { Redistribution from extracellular } \\
\text { into intracellular compartment }\end{array}$ & $\begin{array}{l}\text { Acidosis correction } \\
\text { Re-feeding syndrome } \\
\text { Catecholamine } \\
\text { Accelerated ontogenesis } \\
\text { Endocrine disorders (hyperparathyroidism, malignant hypercalcemia, hyperthyroidism, } \\
\text { aldosteronism, diabetes mellitus) }\end{array}$ \\
\hline Renal losses & $\begin{array}{l}\text { Reduced sodium reabsorption, SIADH } \\
\text { Infusion of saline diuretics } \\
\text { Post-obstructive nephropathy } \\
\text { Renal transplantation } \\
\text { Dialysis } \\
\text { Diuretic phase of acute renal failure } \\
\text { Hereditary disorders (e.g., Bartter's syndrome, Gitelman's syndrome) }\end{array}$ \\
\hline Other & $\begin{array}{l}\text { Pancreatitis, burns, excessive sweating } \\
\text { Drugs [diuretics, cytotoxic chemotherapy (cisplatin), EGFR inhibitors, antibiotics beta-adrenergic } \\
\text { agonists, foscarnet, amphotericin B] }\end{array}$ \\
\hline
\end{tabular}

SIADH: syndrome of inappropriate secretion of antidiuretic hormone

cardiac arrhythmia, disorientation, irritability, tremors, tetany, athetosis, jerking, and confusion, as well as eventually hallucinations, depression, and epileptic crisis. Furthermore, hypomagnesemia is often associated with multiple biochemical alterations, such as hypokalemia, hypocalcemia, and metabolic acidosis that might confuse clinical manifestations ${ }^{[160]}$.

Hypomagnesemia might manifest with electrocardiographic alterations such as prolonged PR and QT intervals, $\mathrm{T}$ wave inversion, and ST elevation ${ }^{[161]}$.

The diagnosis is based on the detection of lower serum magnesium levels. For a correct differential diagnosis, data on potential gastrointestinal or renal losses and concomitant drugs should be collected. To distinguish between renal and extra-renal losses, magnesium fractional excretion, and urinary calcium and creatinine should be assessed [Figure 7]. Urine magnesium concentration $>2 \mathrm{mmol} /$ day is due to renal wasting.

Treatment for hypomagnesemia depends on severity and clinical presentations. Underlying disorders causing hypomagnesemia should be corrected ${ }^{[162]}$. Patients with anamnestic risk magnesium deficiency; laboratory tests and clinical symptoms should be monitored and, when indicated, a prophylactic treatment should be considered. For example, in patients receiving cisplatin-based chemotherapy, intravenous supplementation of magnesium on the day of cisplatin administration and 2-3 days after therapy is indicated.

In asymptomatic patients, oral supplementation of magnesium salts should be preferred (40-60 mEq/day); however, diarrhea might represent a dose-limiting adverse event.

In symptomatic patients, infusion of intravenous magnesium sulfate should be preferred. A total of 1-4 $\mathrm{g}$ should be administered with low infusion in $12-24 \mathrm{~h}(1 \mathrm{~g} / \mathrm{h})$, until magnesium levels rise to $1.2 \mathrm{mg} / \mathrm{dL}$.

In the case of severe hypomagnesemia, patients should receive a prompt replacement therapy, in order to prevent cardiac arrhythmias and death ${ }^{[161]}$. A total dose of 4-6 $\mathrm{g}$ of magnesium sulfate is usually required in these cases. 


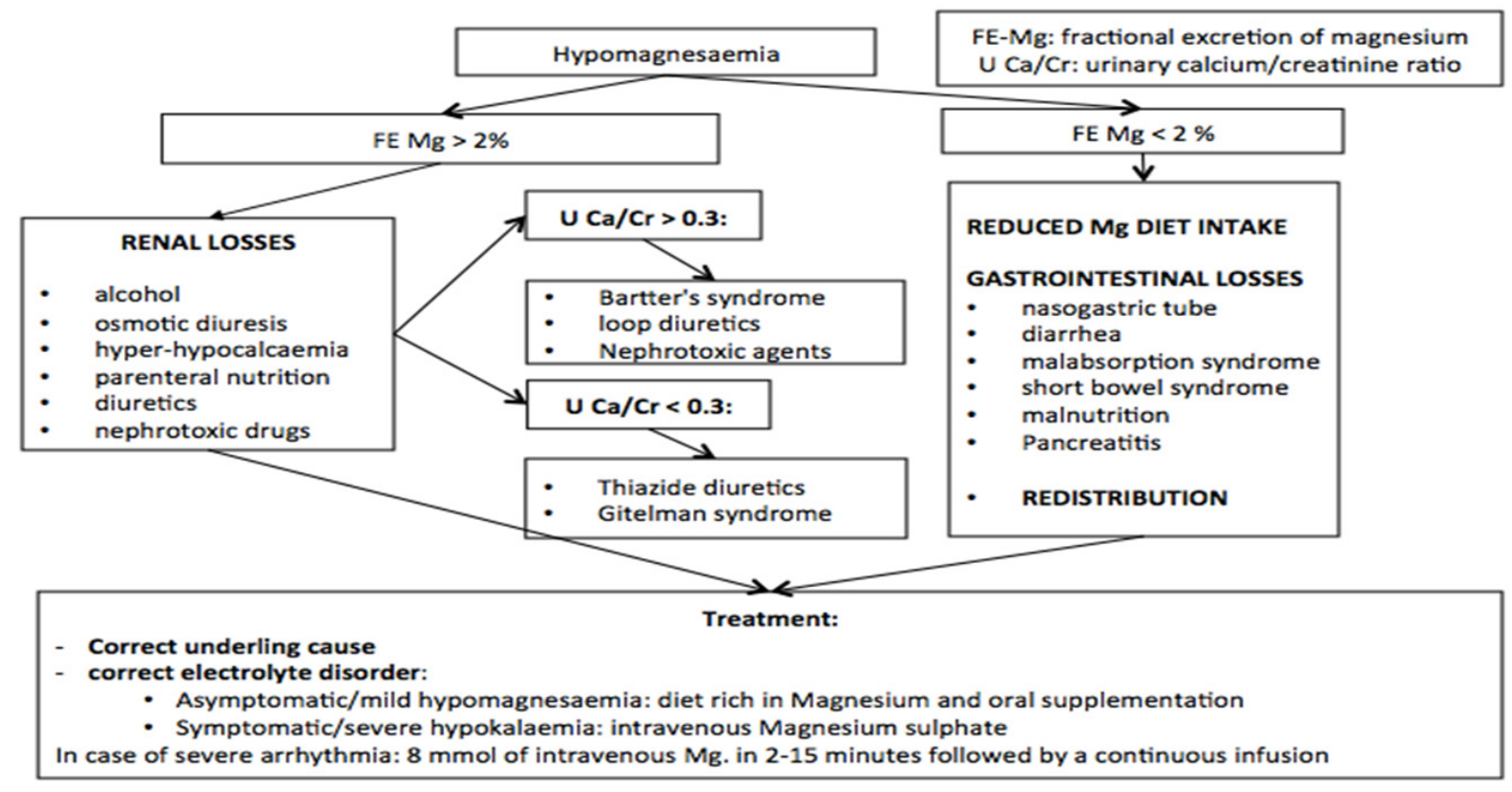

Figure 7. Algorithm of hypomagnesemia management ${ }^{[48,159-162]}$. The treatment of hypomagnesemia is based on the correction of the underlying cause and the integration of magnesium, which can be oral or intravenous based on the degree and symptoms reported. The differential diagnosis of hypomagnesemia is based on fractional excretion of magnesium: if it is $>2 \%$, it might indicate renal loss, while, if it is $<2 \%$, hypomagnesemia might depend on gastrointestinal losses or reduced intake. FE Mg: fractional excretion of magnesium; $U \mathrm{Ca} /$ Cr: urinary calcium/creatinine ratio

The maximum infusion rate should be $8 \mathrm{mEq} / \mathrm{h}$ in asymptomatic patients, since rapid intravenous administration of magnesium sulfate induces elevated serum magnesium levels, which favor magnesium renal excretion. Therefore, a slow infusion is crucial to obtain an adequate correction of hypomagnesemia ${ }^{[163]}$. Concomitant electrolyte disorder and vitamin D deficiency should be corrected ${ }^{[164]}$.

\section{Hypermagnesemia}

Hypermagnesemia is defined as a magnesium plasma level $>2.2 \mathrm{mEq} / \mathrm{L}$. It is a rare electrolyte disorder and is usually iatrogenic (intravenous magnesium, magnesium-containing laxatives, or anti-acids).

Patient with hypomagnesemia might complain of hypotension, respiratory depression, confusion, and ECG alterations such as bradycardia and complete AV-block until asystole. Treatment requires discontinuation of magnesium intake. In symptomatic patients presenting cardiac arrhythmias, respiratory depression, and hypotension, intravenous infusion of calcium gluconate $10 \%$ is suggested. In severe cases, hemodialysis may be necessary ${ }^{[164]}$.

\section{CONCLUSION}

Electrolyte alterations are common disorders in cancer patients and they are demonstrated to worsen prognosis. Altered electrolyte blood balance might depend on the presence of concomitant diseases and treatments, antineoplastic therapies, or paraneoplastic syndrome. Moreover, electrolytic alterations often cause important morbidity, negatively influencing quality of life and possibility of administration and response to the antineoplastic therapies. Furthermore, recent evidence shows the potential role of electrolyte channels in carcinogenesis, suggesting an important role of electrolyte balance in cancer patients. An improvement of knowledge about these conditions is necessary to monitor patients at risk for a prompt diagnosis and effective treatment, in order to improve patient outcome. Considering the lack of data in the literature supported by clinical trials enrolling cancer patients, the treatment recommendations 
are based on retrospective or non-randomized studies such as case reports and case series, and based on clinical recommendations obtained by an Italian group of experts. A recent review analyzed dysnatremia, hypocalcemia, and hypercalcemia in cancer patients ${ }^{[165]}$. Our manuscript deepens understanding of the consequences of electrolytic disturbances on the outcome of cancer patients as well as the roles of ion channels in carcinogenesis. In addition, in this review, the electrolytic disturbances of four cations are analyzed, namely $\mathrm{Na}, \mathrm{K}, \mathrm{Ca}$, and $\mathrm{Mg}$, to try to offer diagnostic and therapeutic algorithms useful for patient management in clinical practice. Prospective studies are needed to improve the management of electrolyte disorders in cancer patients.

\section{DECLARATIONS}

\section{Authors' contributions}

Made substantial contributions to conception and design of the work: Berardi R

Performed acquisition and analysis of data and have drafted the manuscript: Torniai M, Lenci E, Pecci F, Morgese F, Rinaldi S

Revised the manuscript: Berardi R

\section{Availability of data and materials}

Not applicable.

\section{Financial support and sponsorship}

None.

\section{Conflicts of interest}

All authors declared that there are no conflicts of interest.

\section{Ethical approval and consent to participate}

Not applicable.

\section{Consent for publication}

Not applicable.

\section{Copyright}

(c) The Author(s) 2019.

\section{REFERENCES}

1. Berardi R, Rinaldi S, Caramanti M, Grohè C, Santoni M, et al. Hyponatremia in cancer patients: time for a new approach. Crit Rev Oncol Hematol 2016;102:15-25.

2. Liamis G, Filippatos TD, Elisaf MS. Electrolyte disorders associated with the use of anticancer drugs. Eur J Pharmacol 2016;777:78-87.

3. Ingles Garces AH, Ang JE, Ameratunga M, Chénard-Poirier M, Dolling D, et al. A study of 1088 consecutive cases of electrolyte abnormalities in oncology phase I trials. Eur J Cancer 2018;104:32-8.

4. Lastraioli E, Iorio J, Arcangeli A. Ion channel expression as promising cancer biomarker. Biochim Biophys Acta 2015;1848:2685-702.

5. Ko JH, Ko EA, Gu W, Lim I, Bang H, et al. Expression profiling of ion channel genes predicts clinical outcome in breast cancer. Mol Cancer 2013;12:106.

6. Schneider EG, Radke KJ, Ulderich DA, Taylor Jr RE. Effect of osmolality on aldosterone secretion. Endocrinology 1985;116:1621-6.

7. Hall JE, Granger JP, Smith MJ Jr, Premen AJ. Role of renal hemodynamics and arterial pressure in aldosterone "escape". Hypertension 1984;6:1183-92.

8. Robertson GL. Posterior pituitary. In Felig P, Baxter J, Frohman L, editors. Endocrinology and Metabolism. New York: McGraw-Hill; 1995. pp. 385-432.

9. Zhang J, Mao W, Dai Y, Qian C, Dong Y, et al. Voltage-gated sodium channel Nav1.5 promotes proliferation, migration and invasion of oral squamous cell carcinoma. Acta Biochim Biophys Sin (Shanghai) 2019;51:562-70.

10. Fraser SP, Diss JK, Chioni AM, Mycielska ME, Pan H, et al. Voltage-gated sodium channel expression and potentiation of human breast 
cancer metastasis. Clin Cancer Res 2005;11:5381-9.

11. Sanchez-Sandoval AL, Gomora JC. Contribution of voltage-gated sodium channel $\beta$-subunits to cervical cancer cells metastatic behavior. Cancer Cell Int 2019;19:35.

12. Diss JK, Stewart D, Pani F, Foster CS, Walker MM, et al. A potential novel marker for human prostate cancer: voltage-gated sodium channel expression in vivo. Prostate Cancer Prostatic Dis 2005;8:266-73.

13. Campbell TM, Main MJ, Fitzgerald EM. Functional expression of the voltage-gated $\mathrm{Na}^{+}$-channel Nav1.7 is necessary for EGF-mediated invasion in human non-small cell lung cancer cells. J Cell Sci 2013;126:4939-49.

14. House CD, Vaske CJ, Schwartz AM, Obias V, Frank B, et al. Voltage-gated $\mathrm{Na}^{+}$channel SCN5A is a key regulator of a gene transcriptional network that controls colon cancer invasion. Cancer Res 2010;70:6957-67.

15. Argyriou AA, Cavaletti G, Antonacopoulou A, Genazzani AA, Briani C, et al. Voltage-gated sodium channel polymorphisms play a pivotal role in the development of oxaliplatin-induced peripheral neurotoxicity: results from a prospective multicenter study. Cancer 2013;119:3570-7.

16. Otterbach F, Callies R, Adamzik M, Kimmig R, Siffert W, et al. Aquaporin 1 (AQP1) expression is a novel characteristic feature of a particularly aggressive subgroup of basal-like breast carcinomas. Breast Cancer Res Treat 2010;120:67-76.

17. Moon C, Soria JC, Jang SJ, Lee J, Obaidul Hoque M, et al. Involvement of aquaporins in colorectal carcinogenesis. Oncogene 2003;22:6699-703.

18. Wang P, Zhang C, Yu P, Tang B, Liu T, et al. Regulation of colon cancer cell migration and invasion by CLIC1-mediated RVD. Mol Cell Biochem 2012;365:313-21.

19. Li A, Lu D, Zhang Y, Li J, Fang Y, et al. Critical role of aquaporin-3 in epidermal growth factor-induced migration of colorectal carcinoma cells and its clinical significance. Oncol Rep 2013;29:535-40.

20. Dou R, Deng Y, Huang L, Fu S, Tan S, et al. Multi-microarray identifies lower AQP9 expression in adjuvant chemotherapy nonresponders with stage III colorectal cancer. Cancer Lett 2013;336:106-13.

21. Liu S, Zhang S, Jiang H, Yang Y, Jiang Y. Co-expression of AQP3 and AQP5 in esophageal squamous cell carcinoma correlates with aggressive tumor progression and poor prognosis. Med Oncol 2013;30:636.

22. Shen L, Zhu Z, Huang Y, Shu Y, Sun M, et al. Expression profile of multiple aquaporins in human gastric carcinoma and its clinical significance. Biomed Pharmacother 2010;64:313-8.

23. Ayaz M, Karabagli H, Yanardag SB. Can hypo/hypernatremic conditions be a factor for Na ion channel kinetics: model study. Turk Neurosurg 2018;28:421-7.

24. Ouwerkerk R, and Morgan RH. 23Na MRI: from research to clinical use. J Am Coll Radiol 2007;4:739-41.

25. Palmer BF. Hyponatremia in patients with central nervous system disease: SIADH versus CSW. Trends Endocrinol Metab 2003;14:182-7.

26. Castillo JJ, Vincent M, Justice E. Diagnosis and management of hyponatremia in cancer patients. Oncologist 2012;17:756-65.

27. Berghmans T, Paesmans M, Body JJ. A prospective study on hyponatraemia in medical cancer patients: epidemiology, aetiology and differential diagnosis. Support Care Cancer 2000;8:192-7.

28. Sengupta A, Banerjee SN, Biswas N M, Jash D, Saha K, et al. The incidence of hyponatraemia and its effect on the ECOG performance status among lung cancer patients. J Clin Diagn Res 2013;7:1678-82.

29. Rawson NS, Peto J. An overview of prognostic factors in small cell lung cancer. A report from the subcommittee for the management of lung cancer of the United Kingdom Coordinating Committee on Cancer Research. Br J Cancer 1990;61:597-604.

30. Schutz FA, Xie W, Donskov F, Sircar M, McDermott DF, et al. The impact of low serum sodium on treatment outcome of targeted therapy in metastatic renal cell carcinoma: results from the International Metastatic Renal Cell Cancer Database Consortium. Eur Urol 2014;65:723-30.

31. Berardi R, Caramanti M, Fiordoliva I, Morgese F, Savini A, et al. Hyponatraemia is a predictor of clinical outcome for malignant pleural mesothelioma. Support Care Cancer 2015;23:621-6.

32. Kim HS, Yi SY, Jun HJ, Lee J, Park JO, et al. Clinical outcome of gastric cancer patients with bone marrow metastases. Oncology 2007;73:192-7.

33. Choi JS, Bae EH, Ma SK, Kweon SS, Kim SW. Prognostic impact of hyponatraemia in patients with colorectal cancer. Colorectal Dis 2015;17:409-16.

34. Dhaliwal HS, Rohatiner AZ, Gregory W, Richards MA, Johnson PW, et al. Combination chemotherapy for intermediate and high grade non-Hodgkin's lymphoma. Br J Cancer 1993;68:767-74.

35. Jeppesen AN, Jensen HK, Donskov F, Marcussen N, von der Maase H. Hyponatremia as a prognostic and predictive factor in metastatic renal cell carcinoma. Br J Cancer 2010;102:867-72.

36. Berardi R, Santoni M, Newsom-Davis T, Caramanti M, Rinaldi S, et al. Hyponatremia normalization as an independent prognostic factor in patients with advanced non-small cell lung cancer treated with first-line therapy. Oncotarget 2017;8:23871-9.

37. Berardi R, Caramanti M, Castagnani M, Guglielmi S, Marcucci F, et al. Hyponatremia is a predictor of hospital length and cost of stay and outcome in cancer patients. Support Care Cancer 2015;23:3095-101.

38. Verbalis JG, Goldsmith SR, Greenberg A, Korzelius C, Schrier RW, et al. Diagnosis, evaluation, and treatment of hyponatremia: expert panel recommendations. Am J Med 2013;126:S1-42.

39. Sorensen JB, Andersen MK, Hansen HH. Syndrome of inappropriate secretion of antidiuretic hormone (SIADH) in malignant disease. J Intern Med 1995;238:97-110.

40. Berardi R, Santoni M, Rinaldi S, Nunzi E, Smerilli A, et al. Risk of hyponatraemia in cancer patients treated with targeted therapies: a systematic review and meta-analysis of clinical trials. PLoS One 2016;11:e0152079. 
41. Sata A, Hizuka N, Kawamata T, Hori T, Takano K. Hyponatremia after transsphenoidal surgery for hypothalamo-pituitary tumors. Neuroendocrinology 2006;83:117-22.

42. Oren RM. Hyponatremia in congestive heart failure. Am J Cardiol 2005;95:2B-7B.

43. Gillum DM, Linas SL. Water intoxication in a psychotic patient with normal renal water excretion. Am J Med 1984;77:773-4.

44. Hillier TA, Abbott RD, Berrett EJ. Hyponatremia: evaluating the correction factor for hyperglycemia. Am J Med 1999;106:399-403.

45. Peri A, Grohé C, Berardi R, Runkle I. SIADH: differential diagnosis and clinical management. Endocrine 2017;55:311-9.

46. Cuesta M, Garrahy A, Thompson CJ. SIAD: practical recommendations for diagnosis and management. J Endocrinol Invest 2016;39:991100.

47. Petereit C, Zaba O, Teber I, Luders H, Grohe C. A rapid and efficient way to manage hyponatremia in patients with SIADH and small cell lung cancer: treatment with tolvaptan. BMC Pulm Med 2013;13:55.

48. Berardi R, Armento G, Barni S, Caramanti M, Morgese F, et al. Disordini elettrolitici: raccomandazioni per l'iter diagnostic-terapuetico nel paziente oncologico. AIOM 2018. Available from: https:/www.aiom.it/wp-content/uploads/2018/11/2018_Raccomandazioni_ disordini_elettrolitici_AIOM.pdf [Last accessed on 26 Nov 2019]

49. Goh KP. Management of hyponatremia. Am Fam Phys 2004;69:2387-94.

50. Kraft MD, Btaiche IF, Sacks GS, Kudsk KA. Treatment of electrolyte disorders in adult patients in the intensive care unit. Am J Health Syst Pharm 2005;62:1663-82.

51. Snyder NA, Feigal DW, Arieff AI. Hypernatremia in elderly patients. A heterogenous, morbid, and iatrogenic entity. Ann Intern Med 1987;107:309-19.

52. Kahn T. Hypernatremia in hospitalized patients: a sequel of inadvertent fluid administration - reply. Arch Intern Med 2000;160:1537-8.

53. Gipstein RM, Boyle JD. Hypernatremia complicating prolonged mannitol diuresis. N Engl J Med 1965;272:1116-7.

54. Loh JA, Verbalis JG. Diabetes insipidus as a complication after pituitary surgery. Nat Clin Pract Endocrinol Metab 2007;3:489-94.

55. Lindner G, Kneidinger N, Holzinger U, Druml W, Schwarz C. Tonicity balance in patients with hypernatremia acquired in the intensive care unit. Am J Kidney Dis 2009;54:674-9.

56. Adroguè HJ, Madias EN. Hypernatremia. N Eng J Med 2000;342:1493-9.

57. Liamis G, Filippatos TD, Elisaf MS. Evaluation and treatment of hypernatremia: a practical guide for physicians. Postgrad Med 2016;128:299-306.

58. Rose BD. Clinical physiology of acid-base and electrolyte disorders. 5th ed. New York: Mcgraw-Hill; 2001.

59. Palevsky PM. Hypernatraemia. In Greenberg A, editor. Primer on Kidney Diseases. 2nd ed. San Diego: Academic Press; 1998. pp. 64-71.

60. Sands JM, Bichet DG, American College of P, American Physiological S. Nephrogenic diabetes insipidus. Ann Intern Med 2006;144:186-94.

61. Bailey RL, Dodd KW, Goldman JA, Gahche JJ, Dwyer JT, et al. Estimation of total usual calcium and vitamin D intakes in the United States. J Nutr 2010;140:817-22.

62. Ashajyothi A, Pippalla RS, Satyavati D. Osteoporosis - an overview. IJPT 2010;2:847-61.

63. Carney SL. Calcitonin and human renal calcium and electrolyte transport. Miner Electrolyte Meta 1997;23:43-7.

64. DeLuca HF. Evolution of our understanding of vitamin D. Nutr Rev 2008;66:S73-87.

65. Rizzuto R, Pozzan T. Microdomains of intracellular $\mathrm{Ca}^{2+}$ : molecular determinants and functional consequences. Physiol Rev 2006;86:369408.

66. Grice DM, Vetter I, Faddy HM, Kenny PA, Roberts-Thomson SJ, et al. Golgi calcium pump secretory pathway calcium ATPase 1 (SPCA1) is a key regulator of insulin-like growth factor receptor (IGF1R) processing in the basal-like breast cancer cell line MDA-MB-231. J Biol Chem 2010;285:37458-66.

67. Vanden Abeele F, Zholos A, Bidaux G, Shuba Y, et al. $\mathrm{Ca}^{2+}$-independent phospholipase A2-dependent gating of TRPM8 by lysophospholipids. J Biol Chem 2006;281:40174-82.

68. Chodon D, Guilbert A, Dhennin-Duthille I, Gautier M, Telliez MS, et al. Estrogen regulation of TRPM8 expression in breast cancer cells. BMC Cancer 2010;10:212.

69. Fixemer T, Wissenbach U, Flockerzi V, Bonkhoff $\mathrm{H}$. Expression of the $\mathrm{Ca}^{2+}$-selective cation channel TRPV6 in human prostate cancer: a novel prognostic marker for tumor progression. Oncogene 2003;22:7858-61.

70. Tohme JF, Bilezikian JP. Hypocalcemic emergencies. Endocrinol Metab Clin North Am 1993;22:363-75.

71. Zhu W, Zhong M, Ai Z. Systematic evaluation of prophylactic neck dissection for the treatment of papillary thyroid carcinoma. Jpn J Clin Oncol 2013;43:883-8.

72. Kukreja SC, Shanmugam A, Lad TE. Hypocalcemia in patients with prostate cancer. Calcif Tissue Int 1998;43:340-5.

73. McCormick BB, Davis J, Burns KD. Severe hypocalcemia following denosumab injection in a hemodialysis patient. Am J Kidney Dis 2012;60:626-8.

74. Hanamura M, Iwamoto T, Soga N, Sugimura Y, Okuda M. Risk factors contributing to the development of hypocalcemia after zoledronic acid administration in patients with bone metastases of solid tumor. Biol Pharm Bull 2010;33:721-4.

75. Wang Q, Qi Y, Zhang D, Gong C, Yao A, et al. Electrolyte disorders assessment in solid tumor patients treated with anti-EGFR monoclonal antibodies: a pooled analysis of 25 randomized clinical trials. Tumour Biol 2015;36:3471-82.

76. Tohme JF, Bilezikian JP. Hypocalcemic emergencies. Endocrinol Metab Clin North Am 1993;22:363-75.

77. Favus MJ, Bushinsky DA, Lemann JJ. Chapter 13. Regulation of calcium, magnesium, and phosphate metabolism. Am Soc Bone Miner Res 2006. Available from: http://www.homepages.ucl.ac.uk/ ucgatma/Anat3048/PAPERS\%20etc/ASBMR\%20Primer\%20Ed\%206/ Ch\%2013-18\%20-\%20Mineral\%20Homeostasis.pdf [Last accessed on 26 Nov 2019]

78. Bushinsky DA, Monk RD. Electrolyte quintet: calcium. Lancet 1998;352:306-11. 
79. Shoback D. Clinical practice. Hypoparathyroidism. N Engl J Med 2008;359:391-403.

80. Schafer AL, Shoback DM. Hypocalcemia: diagnosis and treatment. In: De Groot LJ, Chrousos G, Dungan K, Feingold KR, Grossman A, et al, editors. Endotext [Internet]. South Dartmouth (MA): MDText.com, Inc.; 2000-2016. Available from: http://www.ncbi.nlm.nih.gov/ books/NBK279022/. [Last accessed on 26 Nov 2019]

81. Maeda SS, Fortes EM, Oliveira UM, Borba VC, Lazaretti-Castro M. Hypoparathyroidism and pseudohypoparathyroidism. Arq Bras Endocrinol Metabol 2006;50:664-73.

82. Schäffler A. Hormone replacement after thyroid and parathyroid surgery. Dtsch Arztebl Int 2010;107:827-34.

83. Brandi ML, Bilezikian JP, Shoback D, Bouillon R, Clarke BL, et al. Management of hypoparathyroidism: summary statement and guidelines. J Clin Endocrinol Metab 2016;101:2273-83.

84. Fong J, Khan A. Hypocalcemia: updates in diagnosis and management for primary care. Can Fam Physician 2012;58:158-62.

85. Hopper AD, Hadjivassiliou M, Butt S, Sanders DS. Adult coeliac disease. BMJ 2007;335:558-62.

86. Bundred N. Antiresorptive therapies in oncology and their effects on cancer progression. Cancer Treat Rev 2012;38:776-86.

87. Sava L, Pillai S, More U, Sontakke A. Serum calcium measurement: total versus free (ionized) calcium. Indian J Clin Biochem 2005;20:158-61.

88. Shepard MM, Smith JW 3rd. Hypercalcemia. Am J Med Sci 2007;334:381-5.

89. Medas F, Erdas E, Loi G, Podda F, Pisano G, et al. Controversies in the management of parathyroid carcinoma: a case series and review of the literature. Int J Surg 2016;28 Suppl 1:S94-8.

90. Saunders BD, Saunders EF, Gauger PG. Lithium therapy and hyperparathyroidism: an evidence-based assessment. World J Surg 2009;33:2314-23.

91. Reagan P, Pani A, Rosner MH. Approach to diagnosis and treatment of hypercalcemia in a patient with malignancy. Am J Kidney Dis 2014;63:141-7.

92. Liou JH, Cho LC, Hsu YH. Paraneoplastic hypercalcemia with metastatic calcification - clinicopathologic studies. Kaohsiung J Med Sci 2006;22:85-8.

93. Johnson RW, Nguyen MP, Padalecki SS, Grubbs BG, Merkel AR, et al. TGF- $\beta$ promotion of Gli2-induced expression of parathyroid hormone-related protein, an important osteolytic factor in bone metastasis, is independent of canonical hedgehog signaling. Cancer Res 2011;71:822-31.

94. Stewart AF, Adler M, Byers CM, Segre GV, Broadus AE. Calcium homeostasis in immobilization: an example of resorptive hypercalciuria. N Engl J Med 1982;306:1136-40.

95. Wesson LC, Suresh V, Parry RG. Severe hypercalcaemia mimicking acute myocardial infarction. Clin Med (Lond) 2009;9:186-7.

96. Crowley R, Gittoes N. How to approach hypercalcaemia. Clin Med (Lond) 2013;13:287-90.

97. Hagerty DR. Evidence-based treatment of hypercalcemia. Medescape 2009. Available from: https://www.medscape.com/ viewarticle/702842 [Last accessed on 26 Nov 2019]

98. Hosking DJ, Cowley A, Bucknall CA. Rehydration in the treatment of severe hypercalcaemia. Q J Med 1981;50:473-81.

99. LeGrand SB, Leskuski D, Zama I. Narrative review: furosemide for hypercalcemia: an unproven yet common practice. Ann Intern Med 2008;149:259-63.

100. Austin LA, Heath H 3rd. Calcitonin: physiology and pathophysiology. N Engl J Med 1981;304:269-78.

101. Dumon JC, Magritte A, Body JJ. Nasal human calcitonin for tumor-induced hypercalcemia. Calcif Tissue Int 1992;51:18-9.

102. Strumpf M, Kowalski MA, Mundy GR. Effects of glucocorticoids on osteoclast-activating factor. J Lab Clin Med 1978;92:772-8.

103. Santini D, Vespasiani Gentilucci U, Vincenzi B, Picardi A, Vasaturo F, et al. The antineoplastic role of bisphosphonates: from basic research to clinical evidence. Ann Oncol 2003;14:1468-76.

104. Schwartz LM, Woloshin S. Lost in transmission - FDA drug information that never reaches clinicians. N Engl J Med 2009;361:1717-20.

105. Zacchia M, Abategiovanni ML, Stratigis S, Capasso G. Potassium: from physiology to clinical implications. Kidney Dis (Basel) 2016;2:72-9.

106. Eleftheriadis T, Leivaditis K, Antoniadi G, Liakopoulos V. Differential diagnosis of hyperkalemia: an update to a complex problem. Hippokratia 2012;16:294-302.

107. Gennari FJ. Disorders of potassium homeostasis. Hypokalemia and hyperkalemia. Crit Care Clin 2002;18:273-88.

108. Clausen T, Everts ME. Regulation of the Na, K-pump in skeletal muscle. Kidney Int 1989;35:1-13.

109. Haren N, Khorsi H, Faouzi M, Ahidouch A, Sevestre H, et al. Intermediate conductance $\mathrm{Ca}^{2+}$ activated $\mathrm{K}^{+}$channels are expressed and functional in breast adenocarcinomas: correlation with tumour grade and metastasis status. Histol Histopathol 2010;25:1247-55.

110. Altintas DM, Allioli N, Decaussin M, de Bernard S, Ruffion A, et al. Differentially expressed androgen-regulated genes in androgensensitive tissues reveal potential biomarkers of early prostate cancer. PLoS One 2013;8:e66278.

111. Girault A, Privé A, Trinh NT, Bardou O, Ferraro P, et al. Identification of KvLQT1 K ${ }^{+}$channels as new regulators of non-small cell lung cancer cell proliferation and migration. Int J Oncol 2014;44:838-48.

112. Crociani O, Zanieri F, Pillozzi S, Lastraioli E, Stefanini M, et al. hERG1 channels modulate integrin signaling to trigger angiogenesis and tumor progression in colorectal cancer. Sci Rep 2013;3:3308.

113. Ding XW, Wang XG, Luo HS, Tan SY, Gao S, et al. Expression and prognostic roles of Eag1 in resected esophageal squamous cell carcinomas. Dig Dis Sci 2008;53:2039-44.

114. Lastraioli E, Perrone G, Sette A, Fiore A, Crociani O, et al. hERG1 channels drive tumour malignancy and may serve as prognostic factor in pancreatic ductal adenocarcinoma. Br J Cancer 2015;112:1076-87.

115. Shao XD, Wu KC, Guo XZ, Xie MJ, Zhang J, et al. Expression and significance of HERG protein in gastric cancer. Cancer Biol Ther 
2008;7:45-50.

116. Ding XW, Yang WB, Gao S, Wang W, Li Z, et al. Prognostic significance of hERG1 expression in gastric cancer. Dig Dis Sci 2010;55:1004-10.

117. Crociani O, Lastraioli E, Boni L, Pillozzi S, Romoli MR, et al. hERG1 channels regulate VEGF-A secretion in human gastric cancer: clinicopathological correlations and therapeutical implications. Clin Cancer Res 2014;20:1502-12.

118. Ma Y, Hou L, Yu F, Lu G, Qin S, et al. Incidence and physiological mechanism of carboplatin-induced electrolyte abnormality among patients with non-small cell lung cancer. Oncotarget 2017;8:18417-23.

119. Viens P, Thyss A, Garnier G, Ayela P, Lagrange M, et al. GM-CSF treatment and hypokalemia. Ann Intern Med 1989;111:263.

120. Adams PC, Woodhouse KW, Adela M, Parnham A. Exaggerated hypokalaemia in acute myeloid leukaemia. Br Med J (Clin Res Ed) 1981;282:1034-5

121. Stolinsky DC. Emergencies in oncology. Current management. West J Med 1978;129:169-76.

122. Bendlow J, Apps E, Jones LE, Poston GJ. Carcinoid syndrome. Eur J of Surg Oncol 2008;34:289-96.

123. Ikuta S, Yasui C, Kawanaka M, Aihara T, Yoshie H, et al. Watery diarrhea, hypokalemia and achlorhydria syndrome due to an adrenal pheochromocytoma. World J Gastroenterol 2007;13:4649-52.

124. Torpy DJ, Mullen N, Ilias I, Nieman LK. Association of hypertension and hypokalemia with Cushing's syndrome caused by ectopic ACTH secretion: a series of 58 cases. Ann N Y Acad Sci 2001;970:134-44.

125. Born-Frontsberg E, Reincke M, Rump LC, Hahner S, Diederich S, et al; Participants of the German Conn's Registry. Cardiovascular and cerebrovascular comorbidities of hypokalemic and normokalemic primary aldosteronism: results of the German Conn's Registry. J Clin Endocrinol Metab 2009;94:1125-30.

126. Launay-Vacher V, Oudard S, Janus N, Gligorov J, Pourrat X, et al; Renal Insufficiency and Cancer Medications (IRMA) Study Group. Prevalence of Renal Insufficiency in cancer patients and implications for anticancer drug management: the renal insufficiency and anticancer medications (IRMA) study. Cancer 2007;110:1376-84.

127. Filippatos TD, Milionis HJ, Elisaf MS. Alterations in electrolyte equilibrium in patients with acute leukemia. Eur J Haematol 2005;75:449-60.

128. Yamamoto Y, Akashi Y, Minami T, Nozawa M, Kiba K, et al. Serious hypokalemia associated with abiraterone acetate in patients with castration-resistant prostate cancer. Case Rep Urol 2018;2018:1414395.

129. Lim S. Approach to hypokalemia. Acta Med Indones 2007;39:56-64.

130. Kishimoto C, Tamaru K, Kuwahara H. Tall P waves associated with severe hypokalemia and combined electrolyte depletion. J Electrocardiol 2014;47:93-4.

131. Viera AJ, Wouk N. Potassium disorders: hypokalemia and hyperkalemia. Am Fam Physician 2015;92:487-95.

132. Chakraborti S, Chakraborti T, Mandal M, Mandal A, Das S, et al. Protective role of magnesium in the cardiovascular diseases: a review. Mol Cell Biochem 2002;238:163-79.

133. Castro D, Sharma S. Hypokalemia. StatPearls Publishing; 2019.

134. Kruse JA, Carlson RW. Rapid correction of hypokalemia using concentrated intravenous potassium chloride infusions. Arch Intern Med 1990;150:613-7.

135. Huang CL, Kuo E. Mechanism of hypokalemia in magnesium deficiency. J Am Soc Nephrol 2007;18:2649-52.

136. Anthony L, Vinik AI. Evaluating the characteristics and the management of patients with neuroendocrine tumors receiving octreotide LAR during a 6-year period. Pancreas 2011;40:987-94.

137. Su H, Gu Y, Li F, Wang Q, Huang B, et al. The PI3K/AKT/mTOR signaling pathway is overactivated in primary aldosteronism. PLoS One 2013;8:e62399.

138. Biller BM, Grossman AB, Stewart PM, Melmed S, Bertagna X, et al. Treatment of adrenocorticotropin-dependent Cushing's syndrome: a consensus statement. J Clin Endocrinol Metab 2008;93:2454-62.

139. Pessi MA, Zilembo N, Haspinger ER, Molino L, Di Cosimo S, et al. Targeted therapy-induced diarrhea: a review of the literature. Crit Rev Oncol Hematol 2014;90:165-79.

140. Charytan D, Goldfarb DS. Indications for hospitalization of patients with hyperkalemia. Arch Intern Med 2000;160:1605-11.

141. Nagasaki A, Takamine W, Takasu N. Severe hyperkalemia associated with "alternative" nutritional cancer therapy. Clin Nutr 2005;24:864-5.

142. Metzner J, Evans JL, Domino KB. Life-threatening hyperkalemia during radiofrequency ablation of hepatocellular carcinoma. J Clin Anesth 2010;22:473-6.

143. Liamis G, Filippatos TD, Elisaf MS. Electrolyte disorders associated with the use of anticancer drugs. Eur J Pharmacol 2016;777:78-87.

144. Kalemkerian GP, Darwish B, Varterasian ML. Tumor lysis syndrome in small cell carcinoma and other solid tumors. Am J Med 2007;103:363-7.

145. Cairo MS, Coiffier B, Reiter A, Younes A; TLS Expert Panel. Recommendations for the evaluation of risk and prophylaxis of tumour lysis syndrome (TLS) in adults and children with malignant diseases: an expert TLS panel consensus. Br J Haematol 2010;149:578-86.

146. Lam KY, Lo CY. Metastatic tumours of the adrenal glands: a 30-year experience in a teaching hospital. Clin Endocrinol 2002;56:95-101.

147. Bellevue R, Dosik H, Spergel G, Gussoff BD. Pseudohyperkalemia and extreme leukocytosis. J Lab Clin Med 1975;85:660-4.

148. Mattu A, Brady WJ, Robinson DA. Electrocardiographic manifestations of hyperkalemia. Am J Emerg Med 2000;18:721-9.

149. Kim HJ, Han SW. Therapeutic approach to hyperkalemia. Nephron 2002;92:33-40.

150. Weisberg LS. Management of severe hyperkalemia. Crit Care Med 2008;36:3246-51.

151. Fordjour KN, Walton T, Doran JJ. Management of hyperkalemia in hospitalized patients. Am J Med Sci 2014;347:93-100.

152. Ingram TC, Olsson JM. In brief: hypokalemia. Pediatr Rev 2008;29:e50-1. 
153. Ngugi NN, McLigeyo SO, Kayima JK. Treatment of hyperkalaemia by altering the transcellular gradient in patients with renal failure: effect of various therapeutic approaches. East Afr Med J 1997;74:503-9.

154. Walser M. Magnesium metabolism. Ergeb Physiol 1967;59:185-296.

155. Grašič Kuhar C, Strojan P, Zadnik V, Zakotnik B. Importance of magnesium sulfate supplementation in the prevention of hypomagnesemia and hypocalcemia during chemoradiation in head and neck cancer. J Trace Elem Med Biol 2018;50:327-31.

156. Rubeiz GJ, Thill-Baharozian M, Hardie D, Carlson RW. Association of hypomagnesemia and mortality in acutely ill medical patients. Crit Care Med 1993;21:203-9.

157. Lajer H, Kristensen M, Hansen HH, Nielsen S, Frøkiaer J, et al. Magnesium depletion enhances cisplatin-induced nephrotoxicity. Cancer Chemother Pharmacol 2005;56:535-42.

158. Wang Q, Qi Y, Zhang D, Gong C, Yao A, et al. Electrolyte disorders assessment insolid tumor patients treated with anti-EGFR monoclonal antibodies: a pooled analysis of 25 randomized clinical trials. Tumour Biol 2015;36:3471-82.

159. Yu ASL. Disturbances of magnesium metabolism. In: Brenner BM, Rector FC, editors. The Kidney. Saunders 6th ed, Philadelphia; 2000. pp. $1055-70$.

160. Weisinger JR, Bellorín-Font E. Magnesium and phosphorus. Lancet 1998;352:391-6.

161. Noronha JL, Matuschak GM. Magnesium in critical illness: metabolism, assessment, and treatment. Intensive Care Med 2002;28:667-79.

162. Hansen BA, Bruserud Ø. Hypomagnesemia in critically ill patients. J Intensive Care 2018;6:21.

163. Augus ZS. Hypomagnesemia. J Am Soc Nephrol 1999;10:1616-22.

164. Morisaki H, Yamamoto S, Morita Y, Kotake Y, Ochiai R, et al. Hypermagnesemia-induced cardiopulmonary arrest before induction of anesthesia for emergency cesarean section. J Clin Anesth 2000;12:224-6.

165. Khan MI, Dellinger RP, Waguespack SG. Electrolyte disturbances in critically Ill cancer patients: an endocrine perspective. J Intensive Care Med 2018;33:147-58. 